\title{
Perspective on Mechanism Development and Structure-Activity Relationships for Gas-phase Atmospheric Chemistry
}

\author{
L. Vereecken, ${ }^{1}$ B. Aumont, ${ }^{2}$ I. Barnes, ${ }^{3,}$ J. W. Bozzelli, ${ }^{4}$ M. J. Goldman, ${ }^{5}$ W. H. Green, ${ }^{5}$ \\ S. Madronich, ${ }^{6}$ M. R. McGillen, ${ }^{7}$ A. Mellouki, ${ }^{8}$ J. J. Orlando, ${ }^{6}$ B. Picquet-Varrault, ${ }^{2}$ \\ A. R. Rickard,,${ }^{9,10}$ W. R. Stockwell, ${ }^{11}$ T. J. Wallington, ${ }^{12}$ W. P. L. Carter ${ }^{13}$ \\ ${ }^{1}$ Institute for Energy and Climate Research: IEK-8 Troposphere, Forschungszentrum Jülich GmbH, Jülich, Germany \\ ${ }^{2}$ Laboratoire Interuniversitaire des Systèmes Atmosphériques (LISA), UMR 7583 CNRS, Universités Paris-Est Créteil et \\ Paris Diderot, Institut Pierre-Simon Laplace, Créteil Cedex, France \\ ${ }^{3}$ University of Wuppertal, School of Mathematics and Natural Sciences, Physical \& Theoretical Chemistry, Wuppertal, \\ Germany \\ ${ }^{4}$ Department of Chemistry and Environmental Science, New Jersey Institute of Technology, Newark, New Jersey 07102 , \\ USA \\ ${ }^{5}$ Department of Chemical Engineering, Massachusetts Institute of Technology, Cambridge, Massachusetts 02139, USA \\ ${ }^{6}$ Atmospheric Chemistry Observations and Modeling Laboratory, National Center for Atmospheric Research, Boulder, \\ Colorado 80307 USA \\ ${ }^{7}$ School of Chemistry, University of Bristol, Cantock's Close, Bristol, BS8 1TS, United Kingdom \\ ${ }^{8}$ Institut de Combustion, Aérothermique, Réactivité et Environnement (ICARE), CNRS/OSUC, 45071 Orléans Cedex 2, \\ France. \\ ${ }^{9}$ Wolfson Atmospheric Chemistry Laboratories, Department of Chemistry, University of York, York, YO10 5DD, UK \\ ${ }^{10}$ National Centre for Atmospheric Science, University of York, York, YO10 5DD, UK \\ ${ }^{11}$ University of Texas at El Paso, Department of Physics, El Paso, U.S.A. \\ ${ }^{12}$ Research \& Advanced Engineering, Ford Motor Company, Dearborn, MI 48121-2053, USA \\ ${ }^{13}$ College of Engineering, Center for Environmental Research and Technology (CE-CERT), University of California, \\ Riverside, CA, 92521, USA
}

* Deceased, Jan 2018. This perspective is dedicated to the memory of our friend and colleague Ian Barnes, whose comprehensive knowledge and expertise on the understanding and application of atmospheric chemical kinetics and mechanisms has fed into many aspects of this review. 


\section{Contents}

Perspective on Mechanism Development and Structure-Activity Relationships for Gas-phase

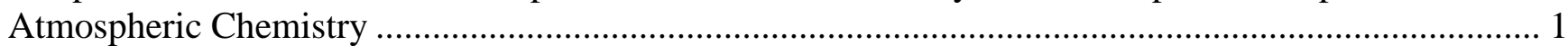

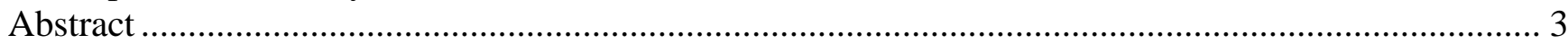

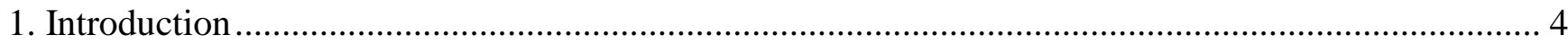

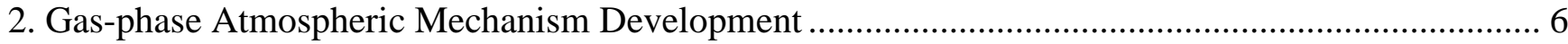

2.a. Summary of Atmospheric reactions of Organic Compounds and Intermediates ........................... 6

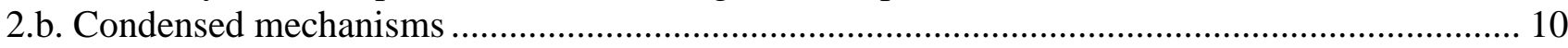

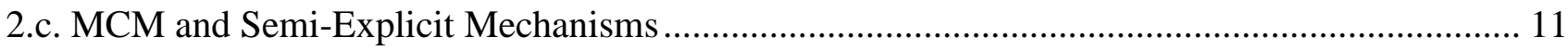

2.d. Automated Mechanism Generation Systems ....................................................................... 12

2.e. Needs and Approaches for Improving Mechanisms ................................................................ 13

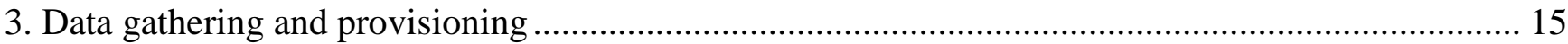

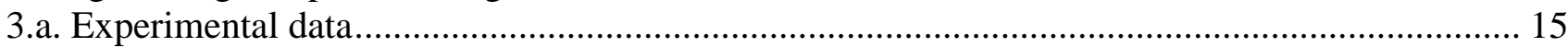

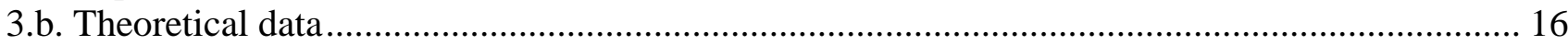

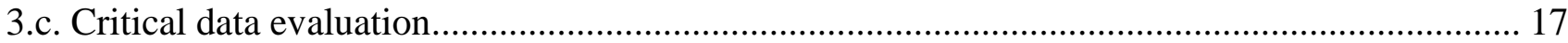

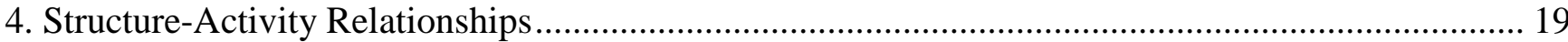

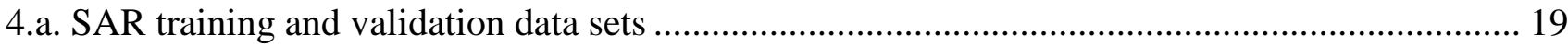

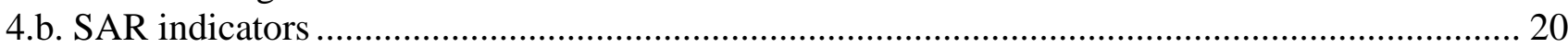

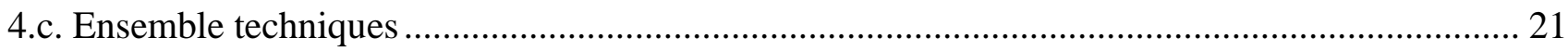

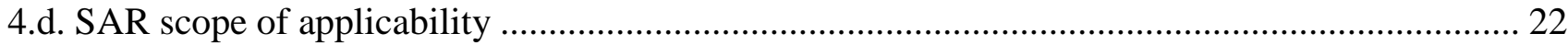

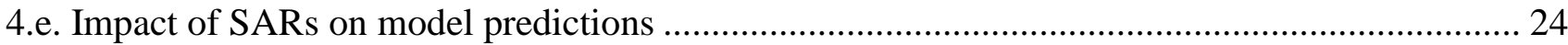

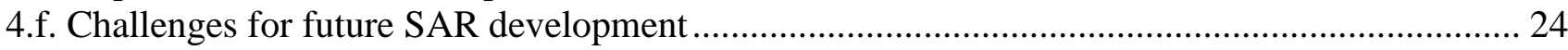

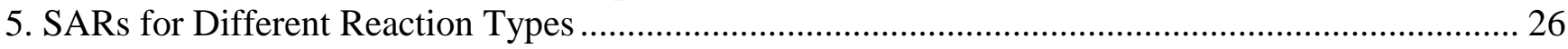

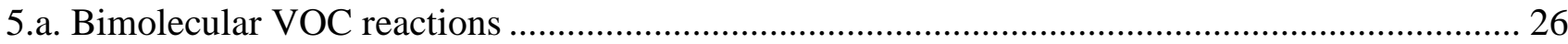

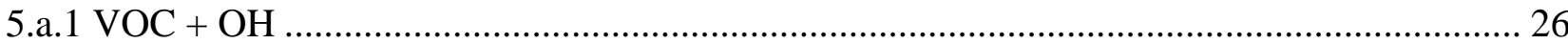

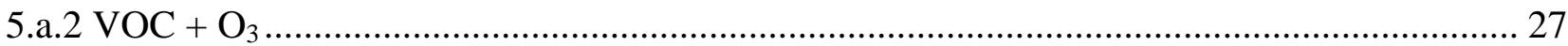

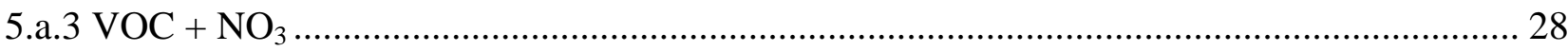

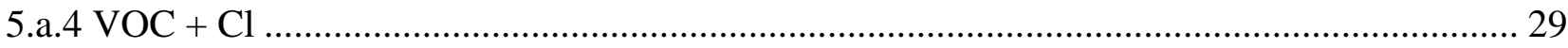

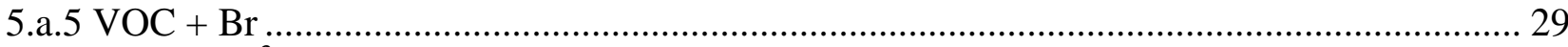

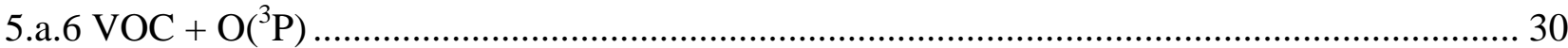

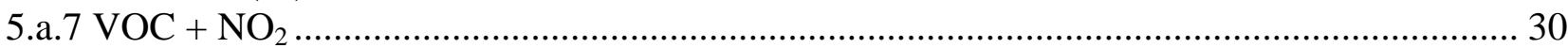

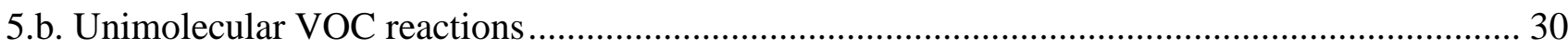

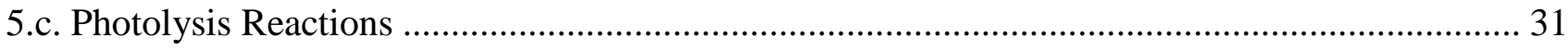

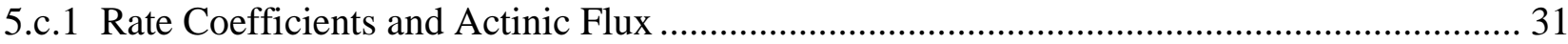

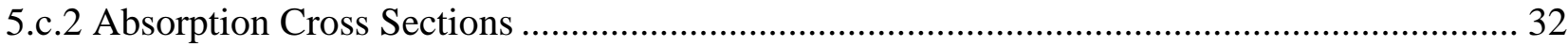

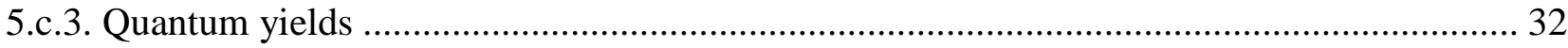

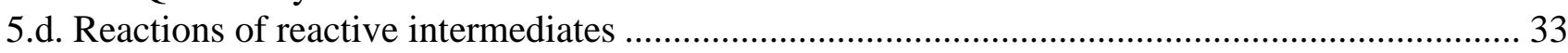

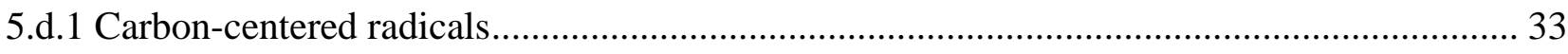

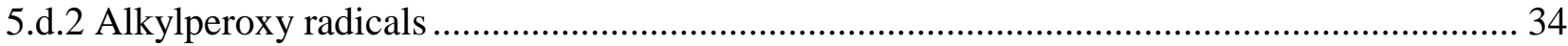

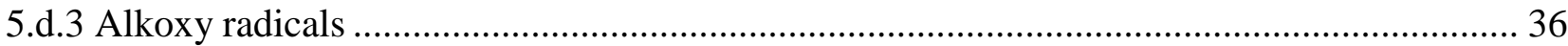

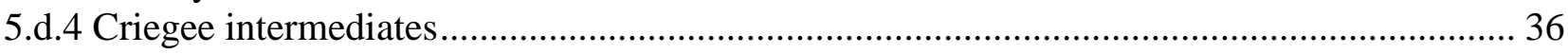

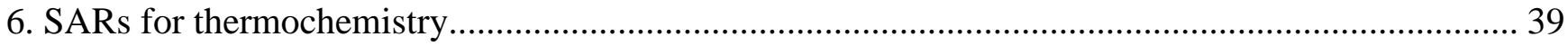

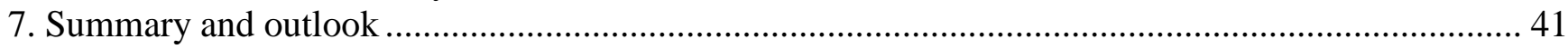

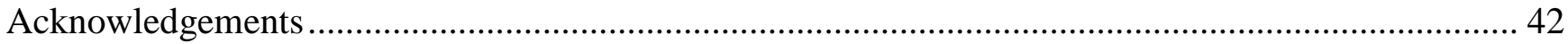

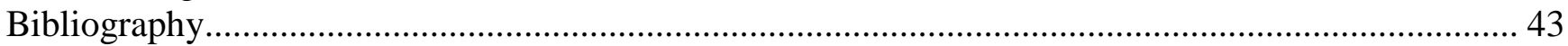




\section{Abstract}

This perspective gives our views on general aspects and future directions of gas-phase atmospheric chemical kinetic mechanism development, emphasizing on the work needed for the sustainable development of chemically detailed mechanisms that reflect current kinetic, mechanistic, and theoretical knowledge. Current and future mechanism development efforts and research needs are discussed, including software-aided auto-generation and maintenance of kinetic models as a futureproof approach for atmospheric model development. There is an overarching need for the evaluation and extension of Structure-Activity Relationships (SARs) that predict the properties and reactions of the many multi-functionalized compounds in the atmosphere that are at the core of detailed mechanisms, but for which no direct chemical data are available. Here, we discuss the experimental and theoretical data needed to support the development of mechanisms and SARs, the types of SARs relevant to atmospheric chemistry, the current status and limitations of SARs for various types of atmospheric reactions, the status of thermochemical estimates needed for mechanism development, and our outlook for the future. The authors have recently formed a SAR evaluation working group to address these issues. 


\section{Introduction}

Atmospheric models are important to our understanding of the formation and the composition of air pollution and our ability to develop appropriate policies to reduce its effects on air quality and health. A critical component of such models is the gas-phase atmospheric chemical mechanism, ${ }^{1}$ which represents how pollutants are transformed in the atmosphere. Secondary pollutants, which are formed in a complex series of reactions of the primary emitted pollutants, usually have significantly more health and environmental effects than primary pollutants. ${ }^{2,3}$ Many hundreds of types of organic compounds are emitted into the atmosphere, ${ }^{4}$ each reacting at different rates and forming different intermediates and oxidized products, in most cases forming products that are also reactive. Most of these promote the formation of ozone when they react in the presence of oxides of nitrogen $\left(\mathrm{NO}_{\mathrm{x}}\right)$ and sunlight, and many also form air toxics, highly oxidized molecules (HOM), secondary organic aerosol (SOA), and contribute to fine particulate matter (PM) pollution. The effects of a compound's emissions on secondary pollutant formation depend not only on the compound and how it reacts, but also the environment where it reacts and the other pollutants that are present. All these effects need to be considered in the chemical mechanism used in the model.

Gas-phase chemical mechanisms used in atmospheric models range in size from the computergenerated GECKO-A mechanisms that include millions of reactions and species but still represent only a subset of types of pollutants present, ${ }^{5}$ through the MCM that has thousands of reactions and species and was developed to be a detailed reference mechanism for atmospheric chemistry research, ${ }^{6,7}$ through the SAPRC mechanisms used to calculate ozone reactivity scales for hundreds of compounds, ${ }^{8,9}$ through more condensed mechanisms used primarily in 3-D models such as the RADM, ${ }^{10}$ RACM, ${ }^{11,12}$ and Carbon Bond series of mechanisms, ${ }^{13,14}$ to very small more parameterized chemical schemes designed for incorporation in large chemical transport and earth system models, such as GEOS-Chem ${ }^{15}$ or UKCA. ${ }^{16,17}$ The most appropriate mechanism reduction approach depends on the model application, with condensed mechanisms generally considered adequate for ozone predictions. More detailed mechanisms are needed for air toxics and SOA prediction. Benchmark mechanisms can be used as a starting point for systematically developing condensed mechanisms optimized for specific applications (as suggested by Kaduwela et al. ${ }^{18}$ ), though this approach has not yet been widely exploited, primarily because of the difficulty in developing comprehensive and reliable detailed mechanisms.

Increased detail in atmospheric chemical mechanisms does not necessarily imply increased accuracy or predictive capability. Almost all rate coefficients and branching ratios in detailed mechanisms have to be estimated, based on data for a much more limited set of reactions of generally simpler molecules. Some aspects of mechanisms, such as reactions of aromatics and unsaturated oxidation products, are so uncertain that the reactions and intermediates assumed are largely speculative. ${ }^{19}$ In those cases, predictions of condensed or parameterized mechanisms adjusted to fit environmental chamber data or other observational constraints are actually more likely to be more reliable than highly detailed explicit mechanisms derived from first principles or systematic estimation protocols. However, condensed mechanisms adjusted to fit chamber data do not give the fundamental insights needed to understand the underlying chemistry, do not predict the chemical compositions of most of the gas-phase and SOA products that are formed, and become increasingly uncertain when they are extrapolated beyond the conditions for which they were evaluated. Therefore, regardless of the mechanism size that is optimum for a particular application, further progress in our ability to understand and predictively model atmospheric chemistry will require the development of reliable mechanisms that can incorporate our emerging knowledge of the underlying basic chemistry.

In this perspective, we outline our views on the current state of play and future directions of atmospheric chemical mechanism development, emphasizing key areas where work is required for the 
development of chemically detailed mechanisms. Our discussion touches upon three main lines: (a) improvements in mechanism development methodologies, including software-aided generation and maintenance of kinetic models; (b) extension and systematic evaluation of Structure-ActivityRelationships (SARs) to support this mechanism development, and (c) evaluation and collection of experimental and theoretical literature data in databases. These aspects are discussed with respect to current challenges. Finally, we summarize current efforts in these areas and provide an outlook for the future. 


\section{Gas-phase Atmospheric Mechanism Development}

\section{2.a. Summary of Atmospheric reactions of Organic Compounds and Intermediates}

Figure 1 shows the main atmospheric reaction cycles in the oxidation of volatile organic compounds (VOCs), Figure 2 shows the basic chemical structures, and Table 1 summarizes the types of reactants and reactions involved. Oxidation is initiated by reactions with reactive oxidants such as $\mathrm{OH}, \mathrm{Cl}, \mathrm{NO}_{3}$ or $\mathrm{O}_{3}$, by photolysis or by unimolecular reactions. In most cases the initial reactions form carboncentered organic radicals that add $\mathrm{O}_{2}$ to form alkylperoxy radicals, $\mathrm{RO}_{2}$, most of which are transformed to an alkoxy radical $\mathrm{RO}^{\circ}$ by reaction with $\mathrm{HO}_{2}, \mathrm{RO}_{2}$ or $\mathrm{NO}$, though $\mathrm{RO}_{2}$ isomerization reactions are now also considered important as a source of highly oxidized compounds under certain reaction conditions. ${ }^{20,21}$ The alkoxy radicals can react in a number of ways, including reacting with $\mathrm{O}_{2}$ to form $\mathrm{HO}_{2}$ and carbonyls, decomposing to form smaller radicals and molecules, or isomerizing to add additional oxygenated functional groups. The decompositions of alkoxy radicals are the most important processes that result in breaking the VOC into smaller molecules; most of the other radical reactions tend to retain the carbon backbone of the reacting molecule by either converting the radical to a carbonyl (e.g., $\left.\mathrm{RO}+\mathrm{O}_{2}\right)$, hydroperoxide $\left(\mathrm{RO}_{2}+\mathrm{HO}_{2}\right)$, or a nitrate $\left(\mathrm{RO}_{2}+\mathrm{NO}\right)$, or by adding additional functional groups through isomerizations of alkoxy or peroxy radicals. The relative importance of these types of processes control the extent to which the reacting molecules break down into smaller products, or add oxygenated or nitrate functional groups and become less volatile highly oxidized molecules that contribute to secondary organic aerosol (SOA) formation. The primary oxidation products can react further, yielding secondary products which undergo their own reactions, forming either more highly oxidized compounds or ultimately breaking down to form $\mathrm{CO}_{2}$ and $\mathrm{H}_{2} \mathrm{O}$. This mix of oxygenation, fragmentation, and molecule growth gives rise to a large variety of compounds in the atmosphere.

How these many processes are represented in models depends on the level of detail in the mechanism. The most detailed mechanisms may represent these reactions and processes explicitly, while more condensed mechanisms may lump the reactions, products, and processes involved, to represent the net effect on formation of species of interest for the model application. However, regardless of the level of detail, the mechanisms need to have appropriate representation of these processes, or the predictions will be incorrect. 


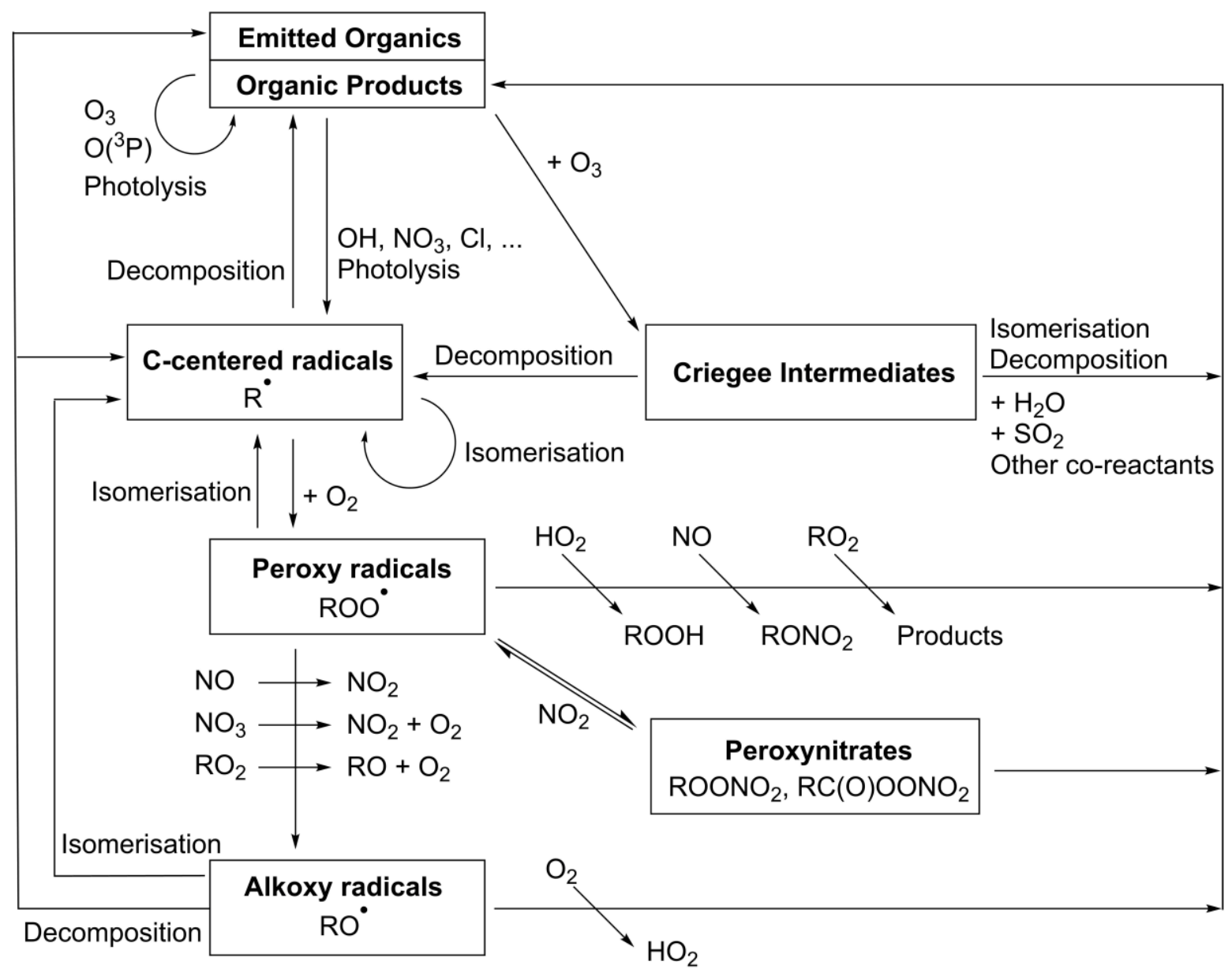

Figure 1. Generalized schematic representation of the atmospheric oxidation cycles for VOCs. 
Hydrocarbon

Oxygenate

Oxidized Nitrogen

Reduced Nitrogen

Radical centers

Criegee

Intermediates

\begin{tabular}{|cccccc|}
\hline $\begin{array}{c}\mathrm{CH}_{3} \\
\text { Aromatic }\end{array}$ & $\begin{array}{c}-\mathrm{CH}_{2}- \\
\mathrm{C}=\mathrm{C}=\mathrm{C}\end{array}$ & $\begin{array}{c}-\mathrm{CH}< \\
\mathrm{C} \equiv \mathrm{C}\end{array}$ & & $\mathrm{C}=\mathrm{C}$ & $\mathrm{C}=\mathrm{C}-\mathrm{C}=\mathrm{C}$ \\
\hline$-\mathrm{CHO}$ & $-\mathrm{C}(\mathrm{O})-$ & $-\mathrm{OH}$ & $-\mathrm{O}-$ & $-\mathrm{OOH}$ & $-\mathrm{OO}-$ \\
$-\mathrm{C}(\mathrm{O}) \mathrm{O}-$ & $-\mathrm{C}(\mathrm{O}) \mathrm{OH}$ & $-\mathrm{C}(\mathrm{O}) \mathrm{OOH}$ & $-\mathrm{OC}(\mathrm{O}) \mathrm{O}-$ & & \\
\hline$-\mathrm{ONO}_{2}$ & $-\mathrm{ONO}$ & $-\mathrm{OONO}_{2}$ & $-\mathrm{OONO}$ & $-\mathrm{NO}_{2}$ & $-\mathrm{NO}$ \\
$\mathrm{C}(\mathrm{O}) \mathrm{OONO}_{2}$ & & & & & \\
\hline
\end{tabular}

\begin{tabular}{|cccccc|}
\hline$-\mathrm{NH}_{2}$ & $-\mathrm{NH}-$ & $-\mathrm{N}<$ & $=\mathrm{NH}$ & $=\mathrm{N}-$ & \\
\hline$-\mathrm{CH}_{2}$ & $-\mathrm{CH}\left({ }^{\bullet}\right)-$ & $>\mathrm{C}\left({ }^{\bullet}\right)-$ & $=\mathrm{CH}^{\bullet}$ & $=\mathrm{C}\left({ }^{\bullet}\right)$ & $-\mathrm{C}(\mathrm{O})^{\bullet}$ \\
$-\mathrm{O}^{\bullet}$ & $-\mathrm{OO}^{\bullet}$ & $-\mathrm{C}(\mathrm{O}) \mathrm{O}^{\bullet}$ & $-\mathrm{C}(\mathrm{O}) \mathrm{OO}$ & $-\mathrm{CH}:$ & $-\mathrm{C}(:)-$ \\
$-\mathrm{NH}^{\bullet}$ & $-\mathrm{N}\left({ }^{\bullet}\right)-$ & $=\mathrm{N}^{\bullet}$ & & & \\
\hline \hline $\mathrm{CH}_{2} \mathrm{O}^{(+)} \mathrm{O}^{(-)}$ & $-\mathrm{CHO}^{(+)} \mathrm{O}^{(-)}($syn-isomer $)$ & $-\mathrm{CHO}^{(+)} \mathrm{O}^{(-)}($anti-isomer $)$ & $>\mathrm{CO}^{(+)} \mathrm{O}^{(-)}$ \\
\hline
\end{tabular}

Figure 2. Chemical structures and functional groups of organic compounds in atmospheric models 
Table 1. Types of reactions that need to be considered when developing atmospheric reaction mechanisms

\begin{tabular}{|c|c|}
\hline Reactants and Reaction Class & Reaction Mechanism \\
\hline \multicolumn{2}{|l|}{ Emitted and oxidized product VOCs } \\
\hline \multicolumn{2}{|l|}{ Bimolecular reactions } \\
\hline Most compounds $+\mathrm{OH}, \mathrm{Cl}$ & H-abstraction \\
\hline \multicolumn{2}{|l|}{ Some compounds $+\mathrm{Br}, \mathrm{NO}_{3}$} \\
\hline $\begin{array}{l}\text { Unsaturated compounds }+\mathrm{OH}, \mathrm{Cl}, \mathrm{Br}, \mathrm{NO}_{3} \text {, } \\
\mathrm{O}_{3}, \mathrm{O}\left({ }^{3} \mathrm{P}\right), \mathrm{NO}_{2}\end{array}$ & Addition to unsaturated bond \\
\hline Aromatic compounds $+\mathrm{OH}$ & Addition to the aromatic ring \\
\hline \multicolumn{2}{|l|}{ Photolysis reactions } \\
\hline Carbonyl compounds & Fragmentation, Isomerization \\
\hline Nitrate, nitrite, peroxy compounds & Fragmentation \\
\hline \multicolumn{2}{|l|}{ Unimolecular reactions } \\
\hline Peroxynitrates & Unimolecular decomposition \\
\hline \multicolumn{2}{|l|}{$\underline{\text { Carbon-centered radicals }\left(\mathrm{R}^{\bullet} \text {, or } \mathrm{RC}(\mathrm{O})^{\bullet}\right)}$} \\
\hline \multicolumn{2}{|l|}{ Reaction with $\mathrm{O}_{2}$} \\
\hline Most carbon-centered radicals & $\mathrm{O}_{2}$ addition forming peroxy radicals \\
\hline$\alpha$-hydroxy alkyl radicals & $\mathrm{H}$-abstraction forming carbonyl $+\mathrm{HO}_{2}$ \\
\hline \multicolumn{2}{|l|}{ Unimolecular reactions } \\
\hline$\alpha$-nitro, $\alpha$-nitrato, $\alpha$-peroxy alkyl radicals & Unimolecular decompositions \\
\hline Unsaturated carbon-centered radicals & Cyclizations \\
\hline$\beta$ cyclopropyl or $\beta$ cyclobutyl radicals & Ring opening with double bond formation \\
\hline$\alpha$-hydroperoxide alkyl radicals & Decomposition forming $\mathrm{OH}$ \\
\hline \multicolumn{2}{|l|}{$\underline{\text { Peroxy radicals }\left(\mathrm{RO}_{2}{ }^{\bullet} \text { or } \mathrm{RC}(\mathrm{O}) \mathrm{O}_{2}{ }^{\circ}\right)}$} \\
\hline Reaction with NO & alkoxy radical formation; Nitrate $\left(\mathrm{RONO}_{2}\right)$ formation. \\
\hline Reaction with $\mathrm{NO}_{2}$ & Peroxynitrate $\left(\mathrm{RO}_{2} \mathrm{NO}_{2}\right)$ formation \\
\hline Reaction with $\mathrm{NO}_{3}$ & Formation of alkoxy radicals $+\mathrm{NO}_{2}$ \\
\hline Reaction with $\mathrm{HO}_{2}$ & Hydroperoxide formation \\
\hline$\alpha$ - or $\beta$-oxygenated $\mathrm{RO}_{2}$ & Formation of $\mathrm{OH} / \mathrm{O}_{3}$ \\
\hline Reaction with $\mathrm{RO}_{2}$ & Formation of alkoxy radicals \\
\hline Reaction with $\mathrm{RO}_{2}$ (if $\alpha-\mathrm{H}$ present) & Formation of carbonyl + alcohol compounds \\
\hline \multicolumn{2}{|l|}{ Unimolecular reactions } \\
\hline Peroxy radicals with weak $\mathrm{X}-\mathrm{H}$ bonds & H-shift isomerizations, forming hydroperoxides \\
\hline Unsaturated peroxy radicals & Ring closure, forming cyclic peroxides \\
\hline \multicolumn{2}{|l|}{ Alkoxy radicals $\left(\mathrm{RO}^{\bullet}\right.$ or $\left.\mathrm{RC}(\mathrm{O}) \mathrm{O}^{\bullet}\right)$} \\
\hline Reaction with $\mathrm{O}_{2}$ (if $\alpha$-H present) & Formation of carbonyl compound $+\mathrm{HO}_{2}$ \\
\hline \multicolumn{2}{|l|}{ Unimolecular reactions } \\
\hline Most alkoxy radicals & $\beta$-scission decomposition \\
\hline Longer chain alkoxy radicals & H-shift isomerization \\
\hline Radicals with $\alpha-\mathrm{H}$ and $\alpha-\mathrm{O}$ atoms & H-atom elimination \\
\hline Radicals with $\alpha-H$ and $\alpha$-ester groups & Ester rearrangement \\
\hline Unsaturated radicals & Ring closure, forming cyclic ethers \\
\hline Excited Criegee intermediates & Decomposition, isomerization, stabilization \\
\hline \multicolumn{2}{|l|}{ Stabilized Criegee intermediates } \\
\hline Unimolecular reactions & Decomposition, isomerization, stabilization \\
\hline $\begin{array}{l}\text { Bimolecular reactions with } \mathrm{H}_{2} \mathrm{O}, \mathrm{SO}_{2} \text {, acids, } \mathrm{H}_{2} \mathrm{O}_{2} \text {, } \\
\text { carbonyl compounds }\end{array}$ & $\begin{array}{l}\mathrm{H}-\text { or O- shift reactions or dimer formation, depending on } \\
\text { reactants }\end{array}$ \\
\hline \multicolumn{2}{|l|}{$\underline{\text { Nitrogen-centered radicals }}$} \\
\hline Reaction with $\mathrm{O}_{2}$ (if $\alpha-\mathrm{H}$ present) & $\mathrm{H}$-abstraction forming $\mathrm{HO}_{2}$ \\
\hline Addition of $\mathrm{NO}$ or $\mathrm{NO}_{2}$ & Formation of nitrosoamines or nitramines \\
\hline
\end{tabular}




\section{2.b. Condensed mechanisms}

Development of gas-phase kinetic mechanisms for air quality models initially focused on developing condensed mechanisms for the prediction of ozone formation. These are based on the assumption that mechanisms of a relatively limited number of selected representative compounds can be used to represent the atmospheric impacts of the much larger number of chemically similar compounds that are emitted or formed in the atmosphere. This approach makes mechanism development much more feasible, given the limited data available concerning the large numbers of compounds involved, and also results in smaller mechanisms that are more computationally efficient. Representative examples include the Carbon Bond mechanisms, ${ }^{13,22}$ the RADM/RACM mechanisms, ${ }^{10,11}$ and the earlier Carter et al. and SAPRC mechanisms ${ }^{23,24}$ These mechanisms vary in the number of model species and representative compounds used in their development, and in some cases in the lumping approach used for higher molecular weight compounds, but they are all based on the assumption that the chemistry of most compounds can be approximated using reactions of chemically similar but simpler or lower molecular weight compounds.

A major objective in developing such mechanisms is that, in addition to being consistent with available data and best estimates for the reactions of the representative compounds, they give appropriate predictions of ozone formation. This is tested by comparing model simulations against ozone formation, $\mathrm{NO}$ oxidation, and reactant consumption in environmental chamber experiments. ${ }^{8,25,26}$ Even though the mechanisms are based on reactions of a relatively limited number of compounds there are still significant uncertainties concerning reactions of some types of those compounds, e.g. aromatics. In those cases simplified representations of the complex processes are used, where, if necessary, parameters representing these processes are adjusted to yield acceptable fits to chamber data. Done appropriately, this can give the model more predictive value for the target observables than would be the case for more detailed but unadjusted mechanisms. This makes such mechanisms more relevant for use in regulatory or research applications where accurate ozone predictions are a key objective.

Although most condensed mechanisms are based on representative lower molecular weight compounds, it is commonly assumed that with appropriate lumping assignments they can also be used to predict ozone formation by more complex ambient mixtures with hundreds of compounds. This is supported by the fact that in most cases models do about as well or better in simulating ozone formation in environmental chamber experiments with complex mixtures as with simpler mixtures. ${ }^{8,25,26} \mathrm{We}$ are also not aware of any studies where more chemically detailed mechanisms, representing more emitted species explicitly, necessarily give ambient ozone predictions that are more consistent with the measurements than the highly condensed mechanisms developed for ozone modeling. Of course, this could be due in part to the role of other uncertainties in ambient models, plus the fact that the lower molecular weight compounds represent a relatively large fraction of total emissions. Also, with highly complex mixtures the representation errors for the various lumped compounds might tend to cancel each other out.

Condensed mechanisms based on representative lower molecular weight compounds are not optimal for predictions of secondary organic aerosol (SOA) formation because they provide only limited information on molecular size, which is critical for estimating the volatility of products. Instead, models using these mechanisms use separate parameterized SOA models to predict aerosol formation. ${ }^{27}$ The parameters affecting SOA yields from emitted compounds are derived from environmental chamber experiments where SOA yields are measured on a compound by compound basis, usually with the compound in question being the only VOC present. Such parameterized models give no information about the chemical composition of the SOA that is formed, and the accuracy of their SOA predictions in the atmosphere is highly uncertain because the SOA parameters were derived from single-compound, generally dry, chamber experiments that may not be good representations of factors 
affecting particle formation in ambient atmospheres. Nevertheless, use of condensed mechanisms combined with separate parameterized SOA models is still the primary method used to model SOA formation for regulatory applications. ${ }^{\text {eg. }}{ }^{27}$ Griffin et al. ${ }^{28}$ also presented a condensed mechanism designed specifically for SOA modeling.

Since organic compounds can vary significantly in their effects on ozone formation, ozone control strategies that take differences in VOC reactivity into account are potentially more effective than those that regulate all VOCs equally. ${ }^{29}$ This requires quantification of ozone impacts of individual compounds, which in turn requires more detailed mechanisms that represent these compounds explicitly rather than representing them based on mechanisms developed for simpler or lower molecular weight compounds. For example, the various SAPRC mechanisms used to develop the Maximum Incremental Reactivity (MIR) and other ozone reactivity scales ${ }^{9,23,30}$ build upon the condensed mechanisms by adding reactions for selected additional compounds for calculating their individual ozone impacts with the minimum necessary increase in mechanism size. The additional reactions use lumped model species to represent the oxidized products formed, so this requires only a few additional reactions and model species for each compound added, and generally only one compound is added at a time. ${ }^{8}$ This therefore is just an extension of the approach used for condensed mechanisms for models. An alternative approach is to use more explicit mechanisms to represent the additional compounds and their oxidation products, as discussed below.

There will always be a need for condensed mechanisms, often targeted to well-defined applications, to fill specific needs in the modeling community. Such mechanisms can be highly tuned to the relevant data to ensure optimal predictive capability. However, their predictions are more uncertain when applied to future atmospheres, i.e. when compositions or levels of emissions change significantly, and most lack the chemical detail needed for predicting toxic products and SOA, or for providing insights needed to interpret laboratory studies.

\section{2.c. MCM and Semi-Explicit Mechanisms}

Semi-explicit mechanisms differ from the condensed mechanisms discussed above in that they attempt to represent each of the major atmospheric reactions of the major emitted species more explicitly, as well as the reactions of the major organic products and reactive intermediates. The objective is to serve as a "reference" mechanism for atmospheric chemistry research, and to make reactivity predictions in models. They are referred to as "semi-explicit" or "near-explicit" because it is not practical to represent all possible compounds, products, and reactions that may occur, and some simplifications are necessary, usually by omitting or lumping of minor routes or second- or later-generation products.

Examples of manually-derived semi-explicit mechanisms include the NCAR master mechanism, ${ }^{31}$ and the Master Chemical Mechanism (MCM) ${ }^{7}$ developed in the UK; the MCM currently being the most widely used of such mechanisms. Although currently too large for routine use in 3-D chemical transport models, it provides a means for predicting chemical detail that is not available in models using more condensed mechanisms, offers the ability to evaluate and assess simpler models to get a quantitative sense of their strengths and weaknesses, as well as forms the basis from which to develop and optimise a range of reduced chemical schemes. It can also be used for making predictions of SOA formation based entirely on chemical mechanistic considerations. The MCM has been incorporated into photochemical trajectory models in order to derive an ozone reactivity scale appropriate for multi-day regional ozone formation conditions in north-west Europe, the so-called Photochemical Ozone Creation Potential (POCP) scale. ${ }^{32}$

The current version of the $\mathrm{MCM}^{7,33}$ was developed manually by applying well-defined protocols for estimating rate coefficients and branching ratios for reactions where no data are available. ${ }^{6,33-36}$ 
Although the objective is to be as explicit as possible, it is necessary to make some condensations and simplifications to keep the mechanism down to a manageable size. This was done, for example, by using a few of the major initial reaction routes to represent all the possible initial reactions of larger molecules, parameterization of the $\mathrm{RO}_{2}$ self- and cross reactions, and by lumping of second and higher generation products. Despite this, the current MCM uses over 6700 model species and 17000 reactions to represent the degradation of 143 emitted VOC species. However, the omission of minor routes means that not all products that may be formed in non-negligible yields are predicted, and the lumping of second and subsequent generation species may result in an under prediction of substituted, multigeneration, highly-oxidized products that can contribute to SOA formation.

The protocols for deriving reactions for the MCM are being updated. ${ }^{37,38}$ It is recognized that the manual method of constructing large and complex reaction mechanisms makes updates difficult, timeconsuming and impractical, especially for larger molecules such as sesquiterpenes, and also impractical if more products formed in subsequent generations are to be represented for improved SOA predictions. Therefore, the current plan is to implement the new and updated MCM mechanism derivation protocols into a computerized mechanism generation system for the purpose of automatically deriving and updating new versions of the MCM. Such systems are discussed in the following section.

\section{2.d. Automated Mechanism Generation Systems}

Efforts to manually develop, update, and maintain explicit and semi-explicit mechanisms are hampered by the extremely large numbers of reactions and species that are predicted if all possible modes of reaction are taken into account. One way to address this is to utilize a computer program to predict all possible or relevant pathways, and include them in the mechanism. Computer tools that implement these sequences can be viewed as expert systems replicating the procedures usually used by chemists to write the list of reactions involved in the oxidation of a given species, as well as the related kinetic parameters. The three main steps include: (1) Identification of every possible reaction pathway based on the chemical structure of the compound; (2) Estimation of the rate coefficients, products and stoichiometric coefficients, based on experimental or theoretical data, or a SAR; and (3) Inclusion or rejection of the reaction into the kinetic model, based on a set of criteria. These steps are repeated for each new product formed up to completion of the full mechanism.

The full set of procedures used to systematically select reaction pathways and reaction rates with automated mechanism generation systems are ideally just implementations of the protocols used when manually deriving explicit mechanisms. The main difference is that well-defined and unambiguous rules, algorithms and computer programs have to be used in place of human expert chemical judgment. If the rules and algorithms appropriately reflect our understanding of atmospheric chemistry then the results should be consistent with the best manually-derived mechanisms, except that more comprehensive mechanisms can be derived with less effort, and the mechanisms are much easier to maintain and update as our knowledge evolves. However, the quality of an automatically generated mechanism depends entirely on the quality and robustness of the underlying protocols and SARs; as discussed extensively in this paper, perfect and universally applicable SARs are not available. It is therefore important that the generator system takes the validity limits of the underlying SARs and rules into account, flagging those instances where large uncertainties are expected. Ideally, human experts should examine the generated mechanisms, but the large size usually makes this impractical.

Automated mechanism generation systems have been extensively used in the field of combustion ${ }^{39}$ and have also been developed for use in atmospheric chemistry. Examples of the latter include the SAPRC $^{\text {e.g. }} 40$ and GECKO-A. ${ }^{\text {e.g. 5,41-43 }}$ systems. The purposes of the two tools are however different. The SAPRC system is used to generate mechanisms of selected compounds up to the first generation of 
non-radical products, with mechanisms derived separately for each emitted compound or oxidized product of interest. In this scheme, most oxidized products are represented using lumped model species, except for product compounds with high formation rates or toxicity concerns. That approach is used for a near-comprehensive variety of precursors, for the purpose of deriving ozone reactivity scales $^{9,30}$ or reduced mechanisms suitable for use in $3 \mathrm{D}$ models. ${ }^{9,44}$ On the other hand, the GECKO-A system is used to describe explicitly the gas phase multigenerational production of organic species and their multiphase partitioning, ${ }^{41,45-47}$ so the reactions of the organic products are also automatically generated. The GECKO-A tool is mostly used to generate the near-explicit chemical schemes for (1) a single parent compound, typically to explore properties of the products and/or to perform comparisons with environmental chamber observations ${ }^{\text {e.g. }}{ }^{41-43,47,48}$ and (2) for a limited subset of representative primary hydrocarbons to explore chemical ageing of air parcels..$^{\text {e.g. }}{ }^{49-51}$ Note that the number of species and reactions that GECKO-A needs to explicitly describe oxidation of organic species grows exponentially with the size of the parent hydrocarbon. Typically, computer memory limitations are encountered for species with more than 9 carbon atoms. ${ }^{5}$ The SAPRC system would generate similar numbers of species and reactions if it were also used to derive complete mechanisms for all the volatile organic products that can be formed.

Because of the extremely large size of atmospheric mechanisms derived using mechanism generation systems, at least some reduction in mechanism size is needed for modeling applications. Even GECKO-A, whose focus is on maximum chemical detail for accurate prediction of condensable organics and aerosols, employs some reduction by lumping of species with large carbon numbers and by not reacting species with very low volatility. The SAPRC system uses much more extensive reduction, since it is essentially used to derive condensed mechanisms that reflect the chemistry incorporated in the detailed mechanism.

The use of mechanism generation systems clearly has the potential for being a useful tool to sustain the development of near-explicit mechanisms such as the MCM. Indeed, the MCM and the GECKO-A development teams recently joined forces ${ }^{52}$ so that the GECKO-A mechanism generation capability can more readily be used with new and updated MCM protocols to expand and update the capabilities of the MCM.

\section{2.e. Needs and Approaches for Improving Mechanisms}

The development of atmospheric kinetic mechanisms requires a careful balance between level of detail, traceability, labor in maintaining and updating the model, ease of use and computational cost, and its applicability to specific applications. Kaduwela et al. ${ }^{18}$ recommended an approach for improving mechanisms that focuses first on developing more accurate explicit or computer-generated mechanisms, evaluating them against available experimental data, and then using them as the basis for developing and evaluating more condensed mechanisms tailored for specific modeling applications. This provides clear and documented connections between kinetic data, theories, environmental chamber data, and kinetic mechanisms used in models. The development of chemical mechanisms of varying complexity is synergetic, where explicit mechanisms could serve as a basis for more reduced mechanisms, and where smaller yet well-tuned domain-specific mechanisms can serve as a validation tool for mechanisms built from elementary reactions. This approach was used in a few studies ${ }^{53-57}$ to assess the strengths and weaknesses of various reduction approaches, and to derive condensed mechanisms based on a systematic reduction from a more detailed scheme.

The chemically detailed mechanisms used as a reference must be consistent with all current kinetic data and theories. Without that, the deduced condensed mechanisms may well have less predictive capability than traditionally developed mechanisms tuned to chamber data. As there will always be a need for condensed mechanisms to fill specific needs in the modeling community, work is also needed 
on methods to derive as accurate as possible condensed mechanisms for specific applications from the detailed mechanisms, and to evaluate complete mechanisms against appropriate experimental data metrics or against specialized condensed mechanisms tuned directly to these data. Although the discussion here focuses primarily on developing detailed mechanisms, how best to develop condensed mechanisms is also an essential area of research for future development of practical mechanisms for modeling.

To sustain the improvement of atmospheric models, it is necessary to build upon as complete a dataset as feasible. Compilations of direct fundamental experimental data have always been available, but do not include all the information present in field data or chamber studies. Theoretical work has in the past often been excluded from the data compilations, but the current performance of theory-based predictions prompts us to consider these as a valuable source of information, complementary to the experimental data. Both approaches have their specific strengths and weaknesses, and require crossvalidation to optimize our knowledge base. As discussed below, extending the data compilations both towards larger data sets as towards different types of data available will be critical to improve our understanding of the chemistry. Such data compilations are the basis of evaluation efforts, crossreferencing the information to identify inconsistencies and reducing the uncertainties by statistical analysis and data mining. These databases can also be valuable in the development of SARs.

Structure-activity relationships, SARs, are perhaps the most elegant representation of our knowledge on a specific reaction class, surpassing the anecdotal in favor of a condensed summary of the reaction trends. SARs are critical tools to predict the chemical reactivity and physical behavior of compounds where direct data are not available. This is necessary for detailed mechanism development because most of the compounds or intermediates whose reactions need to be included in detailed mechanisms have not been studied directly, so their reactions and rate coefficients have to be estimated. The validity and usefulness of a SAR depends on many factors, such as the amount and type of input data, reliability of prediction, scope of applicability, and ease of implementation. Extending existing SARs, and developing new SARs for reaction classes hitherto not covered, in close collaboration with model development, will be an important aspect of improving chemical mechanisms, as discussed in more detail below. 


\section{Data gathering and provisioning}

Chemical mechanism development is highly dependent on the availability of accurate kinetic and mechanistic data for the reactions of interest. This includes data concerning specific reactions in the model, and data needed to support the development of SARs for estimating rate coefficients when data are not available. Modern quantum theoretical calculations have advanced to the point where calculated rate coefficients may be useful for models or SAR development when experimental data are not available or are questionable. To be useful for mechanism development, available relevant experimental and theoretical data need to be compiled and evaluated, and recommendations made on which are most suitable for mechanism or SAR development.

\section{3.a. Experimental data}

By virtue of their empirical basis, SARs are reliant upon experimental data. However, current atmospheric chemical kinetics databases are far from comprehensive and are deficient in four key respects:

1.) There is a large preponderance of measurements at atmospheric pressure and room temperature - a consequence of many of these determinations having been made using laboratory and environmental chamber experiments ${ }^{58}$ limited to standardized conditions, with some exceptions. ${ }^{59-62}$ Given the wide range of temperatures encountered in the atmosphere, knowledge of the room temperature rate coefficient alone is insufficient to assess the overall atmospheric fate of a molecule. To improve the accuracy with which SARs predict the temperature dependence of reactions, it will be necessary to increase the size of the temperature-dependent dataset in general, with special attention being paid to the effects of functional groups, which can exert a major and complicated effect upon the temperature dependence of rate coefficients. ${ }^{\text {e.g. } 63-65}$

2.) Data are limited in terms of chemical functionality, with compounds other than simple hydrocarbons or mono-functional species being underrepresented. This general tendency reflects the difficulties that come from working with multifunctional species, which tend to possess a lower vapor pressure and a higher affinity towards surfaces - problems that are exacerbated by the inevitably high surface-to-volume ratios of laboratory apparatus and the often high reactant concentrations necessary for kinetic measurements. Notwithstanding, highly functionalized species are observed in both gas and particle phases under atmospheric conditions, ${ }^{\text {e.g. }} 66$ and it is becoming increasingly apparent that functionalization is a common fate of VOCs being oxidized in the troposphere. Accordingly, it is necessary to obtain kinetic data on many of these functionalized oxidation products if explicit atmospheric chemical models are to be accurate. It is noted that multi-functionality may affect different mechanisms in different ways. In direct hydrogen abstraction reactions, where the rate coefficient is considered to anticorrelate with the bond dissociation energy of $\mathrm{C}-\mathrm{H}$ bonds, ${ }^{67}$ the impact of substitutions upon these bond strengths must be quantified. Conversely, where abstraction reactions are mediated by pre-reactive complexes, the capacity of both single and multiple functional groups to facilitate the formation of and stabilize these complexes must be quantified. Whereas, for electrophilic addition reactions, where rate coefficients are expected to be proportional to the electron density within the $\pi$-orbitals of the addition site, ${ }^{68-70}$ the net effect of combinations of functional groups on reactivity should be assessed.

Databases on the reactivity of organic radicals (e.g. alkoxy- or peroxy-radicals) are also very limited, especially for functionalized radicals. Branching ratios between decomposition/isomerization/ $\mathrm{O}_{2}$ reaction pathways of alkoxy radicals could yield information on the relative rate, but few data have been provided for functionalized alkoxy radicals, preventing accurate prediction of oxidation products and branching ratios between fragmentation/functionalization pathways. For peroxy radicals, 
autoxidation via $\mathrm{H}$-shift pathways have been shown to play a significant role in the formation of highly oxidized compounds ${ }^{20,21,71}$ and thus to strongly affect SOA formation and composition. While the rate of this process has been shown to be highly dependent on the type of peroxy radicals ${ }^{72,73}$ few data have been provided for functionalized radicals.

3.) In most cases, reactions possess several branching pathways towards products. Measurements of product yields that can be readily interpreted as site-specific rate coefficient ratios for competing reaction channels are far less common than determinations of the total phenomenological rate coefficient, with temperature dependent product measurements being rarer still. ${ }^{\text {cf. }}$ 74,75 These types of experiments can be painstaking and difficult, nevertheless, these measurements are crucial for constructing accurate oxidation mechanisms, and, given the scarcity of such data, future work to augment this dataset is necessary. A larger body of data exists with respect to simulation chamber experiments, such as those supplied by the EUROCHAMP Data Center, ${ }^{76}$ and it is possible that data repositories of this type may be interrogated for helping to constrain branching ratios where more direct experimental approaches have not been utilized.

4.) Recent advances in analytical techniques in terms of specificity and sensitivity are enabling the detection of a much greater range of analytes than ever before. This is particularly the case for high resolution, soft ionization mass spectrometric methods and highly sensitive optical methods, which can be used to quantify more functionalized and/ or transient species. It is therefore to be expected that these types of analytes are currently underrepresented in the chemical databases.

\section{3.b. Theoretical data}

While extensive, reviewed data compilations exist based on experimental work, theoretical work has been much slower to be assimilated into these evaluated compendia. For older calculations, the lower level of theories used led to higher uncertainties, such that relying only on experimental data was often the logical choice. Modern calculations, however, can achieve accuracies that rival or in specific cases even exceed that of direct experimental data. This is particularly true for thermodynamic calculations (discussed in Section 6). These improvements in predictive ability have been driven mostly by the increase of computational power. Energy and molecular property calculations can now be performed, often to chemical accuracy or beyond, using quantum chemical coupled cluster calculations, explicit and local correlation methods, basis set extrapolations, multi-reference wavefunctions, composite methods, and other techniques. Entropy calculations can now account for internal rotations, (multidimensional) tunneling effects, anharmonic vibrations, etc., further improving kinetic predictions. As such, it is becoming worthwhile to include theoretical data in the data compilations systematically. In this section, we summarize the strengths and weaknesses of theoretical work relative to experimental data.

One of the most obvious contributions of theory-based studies is the elucidation of reaction mechanisms. Even at lower levels of theory the main reaction pathways in elementary or compound reactions can be determined, and our understanding of atmospheric chemistry has greatly benefited from this information. Most quantum chemical studies focus on obtaining accurate potential energy surfaces (PES), and increases in computational capabilities and quality of methodologies and software will continue to improve the results in the future. A corollary of mechanistic studies is that theory is typically well-placed to identify and quantify reaction products, an aspect of kinetics that has had mixed success in experimental studies due to the difficulties of observing, identifying and quantifying products, especially for reactive products than easily undergo secondary chemistry. It should be noted that a correct description of a PES remains a highly creative effort, as one can miss important pathways, or struggle with optimizations of the transition states that allow access to specific pathways. Software ${ }^{77-79}$ such as Kinbot and RMG aims to support automatic prediction and characterization of 
elementary reaction steps available to a set of reactants, attenuating the tedium of characterizing wellknown pathways, and allowing increased focus on the more unusual pathways.

Based on the PES, which provides the energetic and rovibrational characteristics of reactants, intermediates, transition states and products, it is possible to predict the temperature- and pressuredependent rate coefficients and product distributions of even very complex reactions. ${ }^{80-82}$ While $a$ priori prediction of absolute rate coefficients rivaling experimental data in accuracy is possible, the computational requirements to do so make it often intractable. Absolute rate coefficients are thus typically better determined experimentally. Theoretical work, on the other hand, is particularly strong in deriving relative rate coefficients. This pertains to data across systematic series of reactants, and for temperature-dependencies of a single reaction. The best of both worlds is then obtained by calibrating theoretical results to accurate experimental rate data, often available only at one temperature and pressure, and subsequently extend to a wider range of reaction conditions. Similar techniques, varying reactants systematically relative to a known reference reaction, allow for extensive structure-activity relationships (SARs) that would be hard to compile purely on experimental data. As product distributions for complex mechanisms are essentially based on relative rates, theory-based product distributions are thus also valuable complements to experimental data. Difficulties still remain in the theoretical treatment of pressure dependencies, as collisional energy transfer parameters remain difficult to predict a priori ${ }^{83,84}$ here, too, calibration to even a single experimental data point can strongly reduce the uncertainties.

There have been as of yet no systematic efforts to compile evaluated theoretical data covering all needs of atmospheric modeling. Systematic theoretical data compilations, however, could prove valuable in the development, evaluation, and validation of the SARs and kinetic models used in atmospheric modeling. Theory-based rate coefficients, T- and P-dependencies, and product distributions could supplement the available experimental data, yielding a more complete reference data set. Barrier heights, reaction energies, and other fundamental properties, while not directly useful in kinetic models, are strongly correlated to reactivity, and can be used to verify or extrapolate trends in SARs. Such systematic data is also useful to identify outliers in the experimental data set, or identify compounds where a simple extrapolation of a SAR is not expected to work.

\section{3.c. Critical data evaluation}

The development and evaluation of SARs used in atmospheric models relies on the availability of reliable kinetic and mechanistic data, requiring critical data evaluation. Such evaluations are available in literature reviews by individuals (e.g., Atkinson, $1986^{85}$ ) and by teams of experts (e.g., Lightfoot et al., 1992 ${ }^{86}$; Calvert et al. ${ }^{2,19,87-89}$; IUPAC ${ }^{90}$; NASA $\left.{ }^{91}\right)$. For bimolecular reactions, the temperature dependence is usually expressed in the normal Arrhenius form, $k(T)=\mathrm{A} \times \exp \left(-\mathrm{E}_{\mathrm{a}} / \mathrm{R} T\right)$. For some bimolecular reactions, temperature dependences are better described by the modified expressions such as $k(T)=\mathrm{C}(T / 298 \mathrm{~K})^{\mathrm{n}} \exp (-\mathrm{D} / T)$ or $k(T)=\mathrm{E} T^{\mathrm{n}} \exp (-\mathrm{F} / T)$. The kinetics of pressure dependent reactions are typically represented using modified versions of the Lindemann-Hinshelwood expression. ${ }^{92}$ Limited temperature dependent data are available for reaction branching ratios and are typically expressed either as Arrhenius expressions for the rates of different reaction channels ${ }^{\text {e.g. }} 90$ or by an Arrhenius expression for the overall rate coefficient together with empirical expressions which fit the observed temperature dependence of branching ratios. ${ }^{\text {e.g. }} 86$

These reviews provide significant added value compared to only tabulated data. For example, in the IUPAC panel the available data for individual reactions are reviewed and a datasheet is constructed which describes the techniques used, the relevant experimental conditions including temperature and pressure, and adds notes on the strengths and weaknesses of the techniques as appropriate. The results of multiple studies are combined, and overall uncertainty limits are assessed for the recommended rate 
coefficients and product branching ratios, including additional uncertainties beyond those reported in the original studies, as deemed appropriate by the reviewers.

In typical evaluations the responsibility for individual reactions, or classes of reactions, is divided amongst the team of experts, which allows for clear division of labor and exploits the various strengths within the team. The IUPAC ${ }^{90}$ and NASA ${ }^{91}$ data evaluation panels have been in existence for 40 years and are the longest standing critical data evaluation activities. ${ }^{93}$ The longevity of these efforts has enabled the development and honing of best practices with recommendations produced and reported in a consistent fashion. Recommendations are updated and published ${ }^{\text {e.g. } 94}$ on a regular basis as new experimental and theoretical data become available, and are available at the IUPAC and NASA data evaluation group websites (http://iupac.pole-ether.fr/ and http://jpldataeval.jpl.nasa.gov/, respectively).

Two significant limitations of current critical data evaluation activities stand out. First, they generally do not cover theoretical data that can be useful for mechanism and SAR development. Second, substantial amounts of time can elapse between updates (typically years), which slows down the rate at which updated science is included in chemical models. Refinement of the evaluation processes are needed to better integrate theoretical data into the evaluations and to facilitate more rapid inclusion of the latest critically evaluated data into chemical models (e.g., providing recommended data in machine readable format). Finally, not all reactions of interest for which data are available are currently included in the evaluations. 


\section{Structure-Activity Relationships}

While extensive data collections exist for many reactions occurring in the atmosphere, experimental and theoretical studies have thus far focused on the primary emitted compounds, and their main reaction products. As mechanisms grow larger and more complex, the combinatorially increasing number of reactions and intermediate oxidation products make it unfeasible to study each reaction in detail. The problem is further exacerbated by difficulties in experimentally or theoretically covering certain reaction conditions, compounds, or reaction classes. Structure-activity relationships, SARs, are thus indispensable in the development of chemical kinetic models, as they allow estimation of missing information and generation of the kinetic model.

SARs reflect the reactivity trends evident in the available data, and aim for a reliable extrapolation of these trends to a wider variety of compounds and/or reaction conditions. The ideal SAR provides accurate kinetic or molecular property predictions for a wide range of compounds, identifies the corresponding product structures, and robustly treats all relevant molecular functionalities (including multi-functional substitutions); we are not aware of any such SARs. The available SARs each have their own scope of applicability, accuracy of prediction, required input parameters, reliability of the underlying training set, and ease of implementation and application. The requirements for a SAR depend on the application. Total rate coefficients may be sufficient for many uses, but often knowledge of the contributions of the multiple underlying product reaction channels is also required.

Historically, SARs were developed based on experimental data, though nowadays the improved quality of theoretical studies makes them an important source of information, especially for reactive or complex species that are not easily accessible experimentally. SARs exist for a very wide variety of reaction classes; those of relevance in atmospheric modeling are mentioned in Section 5. We briefly highlight some aspects related to SAR data sets, chemical indicators, and ensemble techniques. We also briefly address challenges in formulating SARs that cover the current problem domains.

\section{4.a. SAR training and validation data sets}

A prerequisite of SAR development is the availability of a training set comprised of reliable literature data, across a wide range of compounds. For some reaction classes, such as the reaction of VOC with $\mathrm{OH}$, relatively large databases exist with high-quality experimental data. For other reactions, such as alkoxy radical reactions or Criegee intermediate (CI) chemistry, the experimental data is scarcer, but extensive theoretical data exists. Such systematic training sets for a specific reaction class allow for reliable SAR development, at least for the range of substituents across which data are available. For many reactions, unfortunately, there are few data available from which to deduce reactivity trends. Finally, there are situations where a large quantity of reliable data is available, but where the underlying mechanism shows such complexity that it is not immediately obvious how a SAR can be derived; a prime example of this is photolysis. The reliability and extent of the training set affects the reliability of the SAR predictions. Surprisingly, there are few efforts towards systematic reviewing and evaluation of SAR performance.

During SAR development, the SAR predictions are compared statistically against the training set data, i.e. an internal consistency check that mostly evaluates the quality of fitting. Sometimes data are specifically not used in the regression of the model (i.e. validation data) to estimate model error with less bias than the training test data, which can help prevent overfitting of the training data. The validation data are typically similar in functionality to the test data. Lack of validation data outside the range of regression means that most SAR studies do not evaluate the statistical reliability of the SAR as a function of the field of applicability, e.g. as a function of the substitution patterns, or towards multifunctionalization. 
As more direct experimental or theoretical data become available, a re-evaluation of the SAR performance can yield valuable insight at where the largest uncertainties remain, and whether retraining of the SAR becomes necessary. The foremost requirement for such evaluation efforts is the availability of data sets against which to validate the SAR. Absolute rate coefficients for initiation reactions are available in data compilations that are updated regularly. However, relative rate data, product distributions, and theoretical data are often not included, hampering a broad, systematic evaluation of the available SARs. SAR validation and extension is strongly linked to the data gathering needs outlined earlier.

\section{4.b. SAR indicators}

An important aspect of a SAR, both for its reliability as for its implementation, is the choice of chemical indicators used, i.e. which "input variables" are needed to obtain the SAR prediction. Indicators in chemical kinetics can be subdivided into four broad categories. The first group of indicators is based on the molecular graph, e.g. number of double bonds, substituents around the active site, or position of heteroatoms. These indicators are the most accessible and straightforward to implement, making them the most common and popular type of indicators. Group-additivity schemes, which fall under this class of indicators, are the de facto standard in many applications, such as thermodynamics, volatility, or $\mathrm{VOC}+\mathrm{OH}$ reaction rates. Many atmospheric kinetic mechanisms are built upon group-additivity paradigms (e.g. $\mathrm{RMG},{ }^{95} \mathrm{SAPRC}{ }^{44}$ ), where each reactant is characterized as a set of subgroups which determines its applicable reaction classes. The subgroups are not limited to site-specific substituents, but can span functionalization across a larger region of the molecule. Such supergroups ${ }^{\text {e.g. } 96}$ are highly important in characterizing long-distance effects in molecules, such as intramolecular $\mathrm{H}$-bonding, long-range $\mathrm{H}$-migration, etc. It is our recommendation that SAR developments attempt to build upon graph-based indicators, as these are the most easily implemented across the available models and applications. Graph-based indicators are not without problems, however. A particular problem is when the reactivity is determined by subtle interactions between many groups in the model, and many indicators would be needed to capture these effects, increasing the variable count (parameter space dimensionality) of the SAR. In such cases, index-based or quantum chemical indicators (see below) might be more suitable.

The second group of indicators are based upon molecular properties, such as ionization potential (IP), dipole moment, electron affinity, etc. Such indicators were popular to describe the reactivity of e.g. alkoxy radical chemistry. ${ }^{97}$ For modern applications, however, this group of indicators is rarely the best choice. One drawback is that these indicators describe a molecule as a whole, while many compounds have multiple reaction channels available for which site-specific data is required; e.g., IP correlates well to the $\mathrm{OH}$-addition rate onto a double bond, ${ }^{98}$ but describing multiple double bonds using a single IP is not straightforward. As such, we caution against the use of these indicators. Localized values for molecules, like bond dissociation energies, have proven more useful since they provide site-specific values for developing a SAR. Both molecular and local properties are often not available for more complex molecules, in particular for multifunctional compounds. In this case, having a secondary SAR or performing quantum chemical calculations may be necessary, which could result in reduced accuracy or increased computational cost. Potential loss in accuracy should be accounted for when choosing local indicators.

The third group of indicators are topological index-based, such as the Randić, Wiener, or Hammett index. These indices combine several whole molecule properties into a single number, reducing the dimensionality of the SAR fitting procedure and application. These indices are often based on the molecular graph; examples include connectivity indices or $\mathrm{C}: \mathrm{O}: \mathrm{H}$ ratios. The reduced parameter space provided by indices can counter some of the drawbacks of pure graph-based indicators, but this occurs 
often at the cost of rendering the chemical interpretation of the SAR more difficult; it depends strongly on the application whether this is a criterion. In the QSAR community, indices are commonly used, but SARs in the atmospheric community rarely incorporates them, partly because many indices pertain to the molecule as a whole, which is not very informative in determining multiple, competing pathways.

The final group of indicators is based on quantum chemical data; examples are HOMO/LUMO energies, Fukui indices, softness/hardness values, and atomic charge. By definition, these indicators require some type of quantum chemical calculations for each and every molecule the SAR will be applied to. The key advantage of quantum-based indicators is that these can directly probe the wave function of the compounds, incorporating key molecular or group properties more directly. In many ways, one could consider graph-, property-, or index-based indicators as a lower-level attempt to probe the molecular wave function. In practice, many of the commonly used quantum-based indicators are based on relatively low-level quantum chemical calculations, such as semi-empirical methodologies or sometimes DFT. This use of lower-level quantum methodologies introduces its own statistical noise in the SAR, but remains necessary to reduce the computational cost of deriving and applying the SAR. When developing SARs based on quantum-indicators, the level of computation should balance the time necessary to calculate the quantum indicator(s) and the necessary accuracy of the model. One should also consider that the mechanism developers may not have easy access to the computational resources, software, or knowledge needed to obtain the input values for the SAR. Especially for large, autogenerated models the high number of compounds considered may make it problematic to obtain all required input data. As such, the use of quantum-based SARs could hamper adoption of the SARs, and we recommend against its use unless strictly necessary.

Software exists, both commercial and open source, ${ }^{99}$ which, given the molecular graph, can calculate many of the common graph-based, index-based and low-level quantum indicators; in this way hundreds to thousands of indicators can be generated within minutes for any given molecule. This can be highly useful for SAR development for reactions or property classes where chemical intuition has difficulties identifying the most likely correlated indicators. Obviously, traditional multi-variate fitting techniques will rarely be able to handle such a large number of indicators reliably. Important parameters can be chosen manually or more advanced fitting methodologies, such as partial linear regression (PLR), principle component analysis (PCA), or support vector machines (SVM), can deal with these highdimensional parameter spaces. The use of some advanced machine-learning techniques, such as neural networks, can obfuscate the interpretation of the SAR foundation, in addition to complicating its implementation and extension. The goodness of recovery of these deep learning techniques can often be superior to those of more simple indicator-based, pseudo-linear approaches, but at the same time the opacity of the resulting model makes it hard to understand the chemical foundations of the reactivity. This can hide the true scope of applicability of the SAR, and cause problems in the evaluation of the SAR performance as validation data may not be available to probe this range of applicability.

Ideally, the development of SARs should occur in dialogue with mechanism developers to ensure that implementation and application of the SAR remains feasible for practitioners, both for the smaller mechanisms in use in laboratory and chamber studies, as the comprehensive explicit mechanisms that are likely to be created using modern auto-generation model development methodologies.

\section{4.c. Ensemble techniques}

Ensemble techniques aim to combine the output of multiple models into a single supermodel. Typically classed as a machine-learning technique, ensembles can merge the output of the submodels in multiple ways, ranging from simple best-of-class submodel selection, over (weighted) arithmetic averaging across the submodels, to full Bayesian-statistical prediction merging. Compared to any of the submodels separately, the combined model should then have more robust predictions by reducing the 
uncertainty intervals by accounting for all applicable submodel predictions. Trend extrapolation across the submodels could also lead to a broader range of applicability, while analysis of the prediction uncertainties could guide future work to those domains where improvements are most needed. While ensemble techniques are very powerful, and are used extensively in e.g. weather predictions or model

optimizations, ${ }^{\text {e.g. }}$ 100-102 they are rarely used in SAR development in atmospheric chemistry. In practice, insufficiently different SARs are available to devise a meaningful ensemble. Many SARs are derived from the same training set and/or use the same predictors, such that the submodels would not be statistically independent, reducing the benefit. The most promising route might be to use ensemble techniques to combine experimental data to trends obtained from a priori theoretical predictions at various levels of theory. To some extent this is already done when theory-based predictions are adjusted to experimental data to compensate for approximations in the applied methodology, but the full potential has not been realized yet.

\section{4.d. SAR scope of applicability}

For most reaction classes, the smaller reactants have been well studied; this typically includes $\mathrm{C}_{1}$ through $\mathrm{C}_{4}$ hydrocarbons, terpenoids such as isoprene or $\alpha$-pinene, and some anthropogenic aromatic species. Data are more sparse for larger hydrocarbons, such as monoterpenes, sesquiterpenes or (poly-)cyclic species. Likewise, while information is available for smaller hetero-substituted hydrocarbons, larger oxygenates or otherwise substituted compounds have significantly less coverage. A particular challenge for modern atmospheric modeling is the need to describe multi-functional species; these are typically formed in the oxidation of larger anthropogenic and biogenic VOCs. No SARs are currently available that describe the entire range of multi-functionalization needed, mostly due to lack of data upon which to build a SAR (as discussed elsewhere in this text).

The atmospheric chemistry of multi-functional compounds is poorly understood. Figure 2 gives an overview of the basic structures and functionalities currently incorporated into relevant atmospheric mechanisms. A SAR that treats double, triple or higher functionalization combinatorially is not tractable. However, even higher orders of functionalization are expected in the atmospheric aging of larger compounds. Examples of functionalities predicted to be formed in multi-step atmospheric oxidations of organic compounds by current atmospheric mechanism generation systems (see Section 2.d) are shown in Figure 3 and Figure 4. Figure 3 shows the number of organic species with different numbers of functionalities and the frequencies of functional groups generated by the GECKO-A mechanism for $\alpha$-pinene and octane, and Figure 4 shows approximate relative fluxes for formation of compounds and radicals with various combinations of functional groups predicted using an updated version of the SAPRC mechanism generation system that is under development. Both systems predict a large number of reactive, highly substituted compounds and radicals, and while most of these are predicted to have very low concentrations, the combined mass flux through all of these multifunctionalized species is an essential aspect of the VOC oxidation. Analyses of species in the MCM give similar results. A closer look at the cross-functionalization (e.g., see Figure 4) reveals that, as expected, not all combinatorially possible types of molecules are formed, and that furthermore the cross-functionalization is dependent on the molecules included in the model and how many generations of organic reactions are treated explicitly. The illustrations on multi-functionalization given here are only a subset of the information that can be gleaned from software-aided mechanism generators, but it is clear that this type of meta-analysis would prove very valuable for SAR developers. 

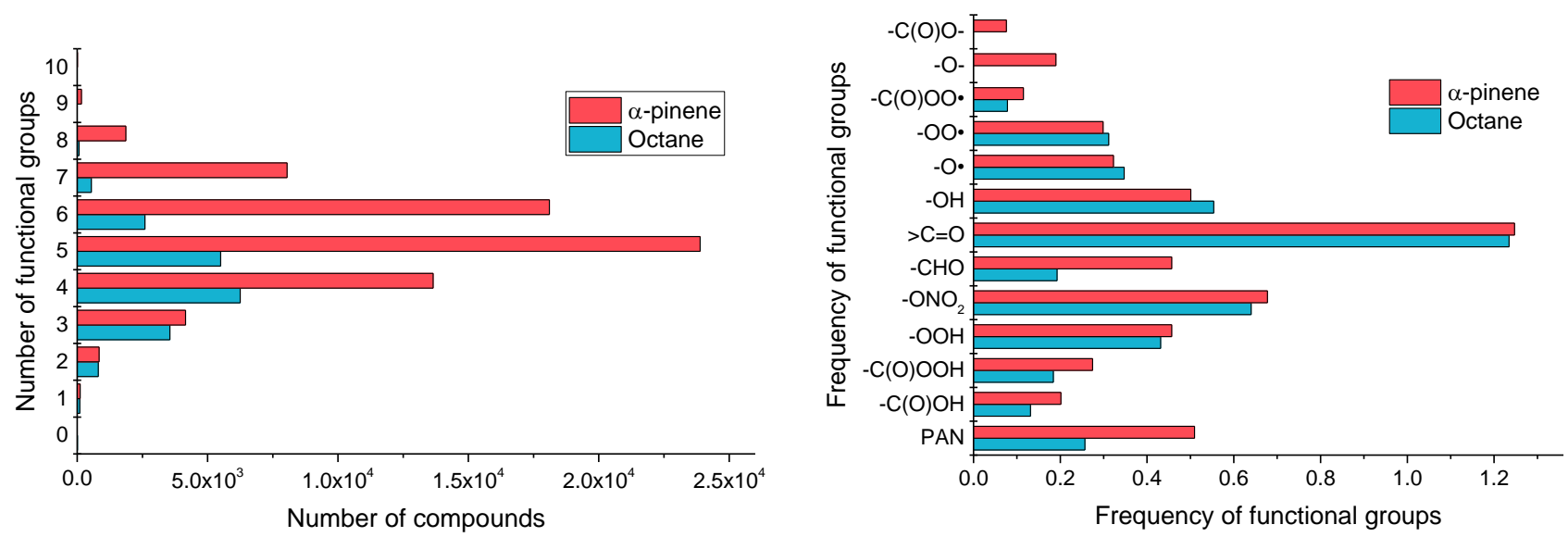

Figure 3: Poly-functionalization in an explicit GECKO-A mechanism for octane and $\alpha$-pinene. Left panel: number of stable and radical compounds in the model, with number of functional groups beyond the hydrocarbon frame. Right panel: Frequency of functional groups, defined as the occurrences of a functional group divided by total number of compounds.

\begin{tabular}{|c|c|c|c|c|c|c|c|c|c|c|c|c|c|c|c|}
\hline Group description & $\begin{array}{l}\text { Group } \\
\text { Pairs }\end{array}$ & $\begin{array}{l}0 \\
\stackrel{1}{2} \\
0 \\
z\end{array}$ & U & \begin{tabular}{l|l}
$\frac{0}{0}$ & 0 \\
$\frac{1}{2}$ & \multicolumn{1}{c}{} \\
& 0
\end{tabular} & 旁 & $\begin{array}{l}\text { I } \\
\text { Oे }\end{array}$ & 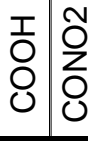 & $\frac{z}{a}$ & $\begin{array}{l}0 \\
0 \\
0\end{array}$ & \begin{tabular}{l|l}
0 \\
O
\end{tabular} & $\begin{array}{lll}0 & 0 \\
& 0 \\
\end{array}$ & 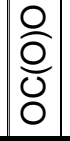 & 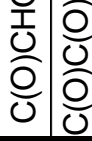 & $\frac{I}{O}$ & $\begin{array}{l}\overline{0} \\
\frac{\partial}{0} \\
\\
\end{array}$ \\
\hline No other substituents & None & & & & & & & & & & & & & & \\
\hline At least one $\mathrm{C}=\mathrm{C}$ bond & $\mathrm{C}=\mathrm{C}$ & & & & & & $\therefore$ & & & & & & & & \\
\hline At least one aromatic ring & Arene & & & & & & & & & & & & & & \\
\hline Aldehyde groups (not dicarbonyl) & $\mathrm{CCHO}$ & & & & & & & & $\because \because$ & $\because$ & & $\therefore$ & & & \\
\hline Ketone groups (not dicarbonyl) & $\mathrm{C}(\mathrm{O}) \mathrm{C}^{\prime}$ & & & & & & & $\therefore:$ & & & & & & & \\
\hline Alcohol groups (not acid) & $\mathrm{COH}$ & & & & & & & & & & & & & & \\
\hline Hydroperoxide groups & $\mathrm{COOH}$ & & & & & & & & $\vdots$ & & $\vdots \vdots$ & $\therefore$ & & & \\
\hline Nitrate groups (not PANs) & CONO2 & & $\therefore$ & $:$ & & & & & & $\vdots$ & & $\vdots \vdots$ & & & \\
\hline Peroxyacylnitrate (PAN) groups & PAN & & & & & 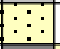 & & & & $:$ & $\vdots \vdots$ & & & & \\
\hline Ether groups (not peroxy, ester) & $\mathrm{COC}$ & & & & & & $\therefore$ & & & & & & & & \\
\hline Peroxy group (not hydroperoxy) & COOC & & & $\therefore$ & & & & & & & & & & & \\
\hline Ester groups (not formate, carbonate) & $\mathrm{C}(\mathrm{O}) \mathrm{OC}$ & & & & & & & $\therefore:$ & & 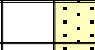 & $\therefore:$ & & $:$ & & \\
\hline Formate groups & $\mathrm{OCHO}$ & & & & & & $\therefore$ & $\vdots \vdots$ & & $\therefore$ & & & & & \\
\hline Carbonate, $-\mathrm{C}(\mathrm{O}) \mathrm{OC}(\mathrm{O})-$, groups & $\mathrm{OC}(\mathrm{O}) \mathrm{O}$ & & & 8 & & & $\therefore$ & & & & & & & & \\
\hline Dicarbonyl aldehyde groups & $\mathrm{C}(\mathrm{O}) \mathrm{CHO}$ & & & & & & & & & & & & $\therefore:$ & & \\
\hline Dicarbonyl ketone & $\mathrm{C}(\mathrm{O}) \mathrm{C}(\mathrm{O})$ & & & & & & & & & $\vdots$ & & $\vdots \vdots$ & & & \\
\hline Carboxylic acid & $\mathrm{C}(\mathrm{O}) \mathrm{OH}$ & & & & & & & & & & & & & & \\
\hline Carboxylic peroxyacids & $\mathrm{C}(\mathrm{O}) \mathrm{OOH}$ & & & & $\because$ & a & & & & & & & & & \\
\hline Two or more other substituents & $3+$ & & & & & & & & & & $\therefore$ & & & & \\
\hline
\end{tabular}

Figure 4. Combinations of functional groups contained in organic product compounds and alkoxy predicted to be formed in the oxidation of a representative anthropogenic VOC mixture to $C_{1}$ or to non-volatile compounds by the updated SAPRC-16 mechanism generation system that is under development. Shading gives a qualitative indication of the relative flux through the radicals or products.

Unfortunately, few SARs clearly state which functionalization is supported, and what the uncertainties are for application outside of the training sets, and few studies exist comparing SARs or evaluating their sensitivities and scope of applicability. This makes it difficult to select the most appropriate SAR 
for a given compound and reaction class. The lack of evaluations of SAR performance with regard to functionalization can lead to improper extrapolation of reaction trends, propagating large errors into kinetic models. It is clear that in this area, much work remains. Research specifically targeted to test and refine the SARs would be of particular value, e.g. studying systematic changes in structure, homologous series, etc. Theoretical studies, which are less limited in the functionalization of their molecules compared to experimental studies, are particularly useful to populate the functionalization grid with training set data.

The poor understanding of the scope of applicability is in part related to an incomplete knowledge of the requirements in the models, i.e. there is significant uncertainty in which molecules we need to examine. There are thousands of molecules emitted into the atmosphere ${ }^{4}$ but only tens of individual molecules are included in explicit mechanisms. Many of the species are assumed to react in a similar way and lumped into a single category. The chemical aging of these leads to increased functionalization, as discussed above. Given the intractably high number of permutations, SARs capable of handling all functionalization are unlikely to be formulated in the near future, but should remain the ultimate goal. However, developing SARs for multi-functional compounds should preferably be performed in close collaboration with mechanism developments, as this will identify which multi-functionalization patterns are most critical, allowing efforts to be focused there where they are most valuable to reduce modeling uncertainties.

\section{4.e. Impact of SARs on model predictions}

The SAR predictions used when developing chemical mechanisms affect model predictions of atmospheric lifetimes and products formed from organic compounds. The uncertainties appear greatest for prediction of the specific oxidation products formed from radicals that have several competing reactions ${ }^{97,103-106}$ (radical rate constants do not affect model predictions if only one reaction dominates). This can have substantial effect on the chemistry in terms of reactivity, ozone and SOA formation potentials, and toxic product formation. Uncertainties in SARs for VOC rate constants affect the prediction of atmospheric lifetimes of emitted and oxidized compounds, particularly for multifunctional oxidized products since the rate constants for the most important primary emitted organics have been measured experimentally.

The uncertainties in estimating rate constants using different types of SARs are discussed in the following sections. A systematic evaluation of the propagation of SAR uncertainty into model predictions would be a large and complex undertaking, since the results would be affected both by the environment being modeled, and the reduction methods used when the chemical mechanism was developed. There have been several studies on how uncertainties in rate constants propagate through to the model predictions, ${ }^{\text {e.g. } 2,107-113}$ but the rate constant uncertainties were not related to SAR uncertainties. A necessary first step in evaluating impacts of SAR uncertainties on model predictions is to evaluate their impacts on predictions of individual rate constants, yet even this has not yet been systematically carried out. Work in this area is ongoing and we expect this to be a subject of subsequent publications. These evaluations can serve as a basis for future studies on effects of these rate constant uncertainties towards model predictions.

\section{4.f. Challenges for future SAR development}

Irrespective of the property predicted by a SAR, how the SAR is implemented has an important impact on its success. In a previous section, we touched upon many aspects of SAR development, ranging from indicators over training methodologies to application methods. Conflicts may arise between the 
need for accurate reproducibility of the underlying data, ease of application in models, chemical understanding incorporated in the SAR model, extensibility of the SAR, and ability of a SAR to deal with new compounds. In atmospheric chemistry, the "Atkinson method" ${ }^{8}$ for estimating rate coefficients based on functional groups at or adjacent to the reaction site is well regarded, as it is easy to implement both by hand and in an automated fashion, using only information based on the molecular graph and a limited set of parameters. Also, it performs reasonably well for the mono-functional compounds. It is, however, not clear if this method will be easy to extend to multi-functional compounds, especially given the small training set available from which to derive cross-substituent parameters or base rate coefficients. The method is known to perform more poorly for some reaction types, e.g. for ozonolysis reactions where steric factors are thought to be important, ${ }^{61,69}$ and similar interactions may be at play in more complex, multi-functionalized species. Implementing SARs in a radically different way, however, is only viable if all parties involved, i.e. SAR developers, model developers, and occasional users, can implement the SAR in a reasonable way to get predictions. This seems to preclude complex predictors, such as properties available only from quantum chemical calculations, as well as complex or opaque numerical procedures such as neural network, even though these often have superior predictive capabilities. Pushing SARs forward to more powerful methodologies, while remaining accessible to all potential users, is a significant challenge; how this proceeds will likely depend on the specific molecular property or reactivity implemented in the SAR.

The challenges faced in atmospheric chemistry are more complex than ever, where highly moleculespecific properties such as health-effects, long-term impact, and multi-phase aging are at the focus of current research. This calls for a significant increase in SAR detail. An example are the many SARs which predict the total rate coefficient of a VOC $+\mathrm{OH}$ reaction, whereas newer SARs will need to be site-specific across the multiple molecular components that allow for abstraction or addition.

Significantly less information is available for site-specific rather than for overall molecular reactivity, and more complex analysis will be necessary to mine the data for the needed correlations. Many reactions also proceed, fully or partially, by chemically activated reactions, which by its very nature depends strongly on the exact molecular framework. An excellent example is the ozonolysis of VOCs, where the yield of $\mathrm{OH}$, stabilized Criegee intermediates, carbonyls, acids and esters, secondary ozonides, and a host of fragmentation products are strongly dependent on the VOC being ozonized, as well as the temperature and pressure. A second example is photolysis, which likewise proceeds via highly excited intermediates with a wide range of internal energies. Developing SARs for such processes is extremely challenging, and current efforts still show large uncertainties despite the clear need to describe such important processes. 


\section{SARs for Different Reaction Types}

Types of reactions in atmospheric mechanisms are summarized in Section 2.a, and listed in Table 1. These reactions and the current status of SAR developments are discussed below.

\section{5.a. Bimolecular VOC reactions}

The major gas-phase atmospheric loss process for most organic compounds is bimolecular reaction with reactive radicals such as $\mathrm{OH}, \mathrm{NO}_{3}$ or halogen atoms, or reactions with $\mathrm{O}_{3}$. Reactions of VOCs with $\mathrm{O}\left({ }^{3} \mathrm{P}\right)$ and $\mathrm{NO}_{2}$ may also contribute under some conditions, as discussed below. There exists a reasonably large literature database for rate coefficients for these reactions, typically focusing (where applicable) on straight, branched and cyclic alkanes; on straight, branched and cyclic alkenes, dienes and conjugated systems; and on simple monofunctional species. Datasets include the peer reviewed evaluations in the NASA/JPL ${ }^{91}$ and IUPAC ${ }^{90}$ kinetic databases (which now includes rate data recommendations for a range of terpenes and sesquiterpenes), the reviews by Calvert et al. ${ }^{87}$ and Atkinson and Arey, ${ }^{58}$ and the non-evaluated compilations in the Chemical Kinetics Database by the National Institutes of Standards and Technology (NIST). ${ }^{114}$ In this section, we focus predominantly on predictive methods available for reactions not available in these compilations.

\section{5.a.1 VOC + OH}

Reaction with the $\mathrm{OH}$ radical is the largest atmospheric sink for most organic compounds. These reactions occur through two mechanisms: hydrogen abstraction and electrophilic addition.

Hydrogen abstraction is the sole reaction mechanism for saturated VOCs. The rate of reaction is linked to the $\mathrm{C}-\mathrm{H}$ bond strengths in the molecule, which can be affected by the presence of different functional groups. Reactions proceeding via hydrogen abstraction generally have a positive temperature dependence. Functional groups can also increase the reactivity of a site by enabling hydrogen-bonded pre-reactive complexes to form, which is important in alcohol, ether and carboxylic acid oxidation. ${ }^{63-}$ 65,115 These pre-reactive complexes impart a complicated temperature dependence, where low temperatures favor stabilization of complexes, but higher temperatures promote dissociation of these complexes, re-forming reactants in the process. There are numerous SARs for OH hydrogen abstraction available in the literature which include empirical fitting methods based on assigning base reactivities and substitution effects of molecular fragments, ${ }^{68,116}$ the perturbation frontier molecular orbital (PFMO) method, ${ }^{\text {e.g. } 117}$ the use of single topological indices ${ }^{117}$ and combinations of multiple topological indices and molecular descriptors. ${ }^{\text {e.g. }} 118$ Compared with other methods, the group-additivity approach is notable both for its accuracy, its capacity for estimating the site-specific rate coefficients, and ease of use. The SARs from Kwok and Atkinson ${ }^{68}$ provide excellent accuracy at room temperature ( $90 \%$ of estimates are within a factor of 2 of the experimental value for a database of 485 species), and performs well for simple hydrocarbons over large temperature ranges, where curvature in the Arrhenius diagram that arises from quantum tunneling effects is described adequately by the $k(T)=A \times T^{2} \times e^{-E / T}$ expressions that are employed. Estimations of the complicated temperature dependence associated with functionalized species are less robust, leading to a revision of the method to describe the effects of certain substitutions, ${ }^{119}$ where implementation of longer-range interaction parameters leads to an improved, but limited, capacity to estimate the branching ratios of singly functionalized species. ${ }^{63,75}$ However, for the multifunctional species and in particular the hydroxy carbonyls, accurate estimation of rate coefficients does not appear to be possible with their general approach. ${ }^{119}$ Mellouki and coworkers ${ }^{120}$ have also proposed that longer-range activation is important for alcohols, ethers, ketones and esters. Here, the ability of a functional group to influence the reactivity of an alkyl site extends to 
the gamma position, with the effect on the rate coefficient decreasing as the distance of the functional group increases.

For alkenes, addition of the $\mathrm{OH}$ to the unsaturated bond(s) is the dominant pathway, with hydrogen abstraction being minor in all but the most reactive ${ }^{67}$ or bulky substitutions. ${ }^{121}$ Alkyl substitution about the unsaturated bond enhances the rate coefficient substantially due to the electron donating effect of alkyl groups, whereas electron-withdrawing substitutions such as halogens or nitriles reduce the reaction rates substantially. As with abstraction reactions, multiple approaches are available for making estimates, including an extension of the group-additivity approach that ascribes a reactivity to a substituted olefin together with substituent factors for non-alkyl substitutions, ${ }^{68}$ PFMO approaches, ${ }^{122}$ and topological and molecular index-based approaches using one ${ }^{123}$ or more descriptors. ${ }^{\text {e.g. } 124}$ The method of Kwok and Atkinson ${ }^{68}$ provides no site-specificity for the addition of $\mathrm{OH}$ to each carbon atom of an asymmetrical alkene. In contrast, the SAR of Peeters et al. ${ }^{125}$ provides estimates of the preference of carbon atom in these systems, but this SAR is restricted to simple hydrocarbons.

For arenes, addition is also the dominant mechanism. Because the $\pi$-orbitals are delocalized, addition reactions are slower than those of the alkenes. It has been noted previously that the arene reactions possess negative temperature dependencies at low temperature (resulting from stabilization of prereactive complexes), positive temperature dependencies at high temperature (where hydrogen abstraction becomes more important) and a transitional temperature regime (where redissociation of $\mathrm{OH}$-arene adducts becomes important). Substitution patterns affect the reactivity of the arenes, and as with the alkenes, electron-donating and withdrawing substitutions influence the rate coefficient. There are comparatively few methods for estimating arene $+\mathrm{OH}$ rate coefficients. The SAR of McGillen et al. ${ }^{126}$ based on a single topological index is restricted to compounds that contain carbon and hydrogen only, with no prediction of the product distribution. The SAR of Zetzsch ${ }^{127}$ can be applied to more compounds, as its estimates of reaction rates are based on Hammett $\sigma^{*}$ substituent constants which are available for a large range of substituents. Zetzsch postulates that where addition sites are nonequivalent, the $\mathrm{OH}$ radical will preferentially add to the carbon with the most negative value of $\Sigma \sigma^{*}$, but does not predict the statistical distribution among possible addition sites.

\section{5.a.2 VOC $+\mathrm{O}_{3}$}

The ozonolysis of unsaturated VOCs is probably the most complex, non-divisible reaction mechanism in the atmosphere, typically proceeding over more than 5 chemically activated intermediates, with excitation energies as high as $100 \mathrm{kcal} \mathrm{mol}^{-1} .{ }^{128,129}$ The initial reaction proceeds through the concerted 1,3-dipolar cycloaddition of ozone to the double bond, forming an energy-rich primary ozonide $(1,2,3$ trioxolane, POZ). The POZ then rapidly dissociates to yield stable primary carbonyl species and Criegee intermediate (CI) co-products, the majority of which are formed in an excited state. The identity of these species is determined by the structure of the parent alkene. ${ }^{129}$ As discussed in more detail in the Criegee Intermediate section (5.d.4), products formed in the decomposition of the POZ can exhibit a wide range of internal energies, which will strongly affect their chemistry. In smaller alkenes, most of the energy partitions into the CI and simple SARs can be used to derive the initial product branching based on the structure of the parent alkene, using measurements of primary carbonyl products assumed to be formed in $100 \%$ total yield. ${ }^{130}$ For asymmetrical poly-olefinic species, this approach is hampered by the uncertainty surrounding the decomposition of the POZ towards products. Taking isoprene as an example, the yield of methacrolein is higher than that of methyl vinyl ketone (0.42 vs 0.17$),{ }^{131}$ with formaldehyde constituting the remainder of the primary carbonyl formed. This may indicate that, for this conjugated dialkene, the less substituted olefinic bond is the dominant reaction site, as suggested by Lewin et al. ${ }^{132}$ However, a second possibility is that formaldehyde represents a preferred leaving group from the more substituted POZ, with the reactivity of the more 
substituted olefinic bond being higher than the methyl vinyl ketone yield would suggest. In systems such as these, a more comprehensive product study that accounts for both the carbonyl and CI fragments is more informative. ${ }^{131}$

As with the equivalent electrophilic addition reactions of the $\mathrm{OH}, \mathrm{Cl}$ and $\mathrm{NO}_{3}$ to olefinic bonds, the rate of reaction with $\mathrm{O}_{3}$ depends strongly on the number and nature of the alkyl substituents attached, reflected in the electron density of the double bond. ${ }^{6,87,133}$ There are a range of SAR approaches available in the literature for estimating rate coefficients for alkene ozonolysis, including simple SARs based on generic alkene structures, ${ }^{\text {e.g. } 5,6,87,134}$ Frontier Molecular Orbital correlations, ${ }^{\text {e.g. }}$ 123,132,133,135-138 and topological indices approaches. ${ }^{\text {e.g. } 69,123}$ Ozone SAR correlation plots exhibit more scatter than for $\mathrm{OH}$ and $\mathrm{NO}_{3}$. Some of this scatter may be attributed to experimental difficulties. For example, some earlier literature rate coefficients do not take into account the formation of $\mathrm{OH}$ radicals from the decomposition of the stabilized CIs formed in the ozonolysis reaction, therefore it is possible that these measurements suffer from interferences. To alleviate this potential problem, ozone rate coefficients are now usually measured in the presence of $\mathrm{OH}$ scavengers. Another source of scatter in this relationship is that the steric requirements for the concerted 1,3-dipolar cycloaddition mechanism are more stringent than for other addition reactions. Working under this hypothesis, McGillen and coworkers ${ }^{61,69,70}$ were able to produce relatively precise SARs for olefins and functionalized alkenes using a geometric description of the substitutions around olefinic bonds. The steric effect proposed by these studies was found to be less pronounced for alkenes containing heteroatomic functional groups, which results from the larger range of inductive effects experienced by olefinic bonds in these molecules, which tends to dominate other factors that control the reaction rate. A further complication in the ozonolysis mechanism may arise from its sensitivity to asymmetry of the $\pi$-bond, as well as ring-strain effects playing an important role in e.g. the terpenoids. ${ }^{132,133,139}$ A major limitation of current ozonolysis SARs is that they are not site-specific. The SARs of McGillen and coworkers, however, represent averages of indices calculated separately for each of the olefinic bonds contained within a molecule; the ratio between these indices could yield an estimate of the expected site-specificity.

\section{5.a.3 VOC $+\mathrm{NO}_{3}$}

The $\mathrm{NO}_{3}$ radical plays an important role in night-time chemistry and is a very efficient sink for unsaturated VOCs that react rapidly with $\mathrm{NO}_{3}$. Reactions of $\mathrm{NO}_{3}$ with VOCs, in particular, with biogenic VOCs (BVOCs), have received increased attention in the recent literature as these processes have been shown to be an important source of organic nitrates and SOA. ${ }^{140}$ However, $\mathrm{NO}_{3}$ chemistry remains much less understood than $\mathrm{OH}$ chemistry, the main uncertainties being the identity of the products and the mechanisms leading to their production. One of the main reasons for the uncertainties is that organic nitrates are very difficult to detect and quantify due to the lack of standards. Hence, mechanistic studies are often limited to the determination of total organic nitrates and SOA yields without any detection or quantification of individual nitrate species. ${ }^{140}$ For this reason, reaction path branching ratios for different reaction sites are rarely available and SAR parameterizations are mainly based on global kinetic data. In addition, few data are available for multifunctional species, which precludes a robust validation of $\mathrm{NO}_{3} \mathrm{SARs} . \mathrm{NO}_{3}$ reactions exhibit a much larger range of rate coefficients in comparison to $\mathrm{OH}$ chemistry, ranging from $10^{-18} \mathrm{~cm}^{3}$ molecule $\mathrm{s}^{-1}$ for short-chain alkanes to $10^{-10}$ for some terpenes. This implies that rate coefficients are very sensitive to the chemical structure, requiring accurate determination of SAR parameters.

Several SARs have been developed to predict rate coefficients for the reactions of $\mathrm{NO}_{3}$ with VOCs. These are based on molecular graphs and group additivity methods, ${ }^{141}$ molecular properties, such as the ionization potential, ${ }^{142}$ a topological index ${ }^{123}$ and quantum-based indicators. ${ }^{122,143,144}$ The reliability and scope of applicability of these SARs are variable and very dependent on the method applied. The 
method proposed by McGillen et al. ${ }^{117,123}$ based on Randić and Balaban topological descriptors has been shown by the authors not to provide reliable estimates. Methods based on quantum calculation developed by Gramatica et al. ${ }^{145}$ for aliphatic and aromatic compounds and by King et al. ${ }^{135,143}$ and Pfrang et al. ${ }^{122,136}$ for alkenes provide good results. The method proposed by Pfrang et al., based on correlations with HOMO energy, has also been extended to several families of oxygenated species (esters, ketones and ethers). ${ }^{137,138}$ The method developed by Kerdouci et al. ${ }^{141,146}$ is based on the group additivity method and is quite similar to that developed by Atkinson and al. ${ }^{116}$ for $\mathrm{OH}$ chemistry. It was initially developed for alkanes, alkenes, and oxygenated species (alcohols, esters, ethers, ketones) ${ }^{141}$ and has since been extended to include saturated and unsaturated aldehydes. ${ }^{146}$ The level of agreement between the measured and estimated rate coefficients is generally good even for the few bifunctional species for which experimental data are available. However, whatever the method, a number of functional groups are not parameterized (nitrate, nitro, amine, alkyl sulfides, thioethers, halogens, ...) thus limiting the range of applicability of these SARs. For empirical SARs, this limitation is attributable to the lack of experimental data. To improve the accuracy and the scope of applicability of the SARs, new experimental data or quantum calculations for mono-and multifunctional species are necessary. These data should include not only overall rate coefficients but site-specific information.

\section{5.a.4 VOC + Cl}

Reactions of Cl-atoms with VOC are of some atmospheric significance, with ubiquitous sources arising from condensed-phase reactions of $\mathrm{Cl}^{-}$ions with $\mathrm{N}_{2} \mathrm{O}_{5}$ in the nighttime atmosphere, from sea-salt based chemistry in the marine boundary layer, and from dissociation of $\mathrm{ClNO}_{2} \cdot{ }^{2,147}$ As with $\mathrm{OH}, \mathrm{NO}_{3}$, and $\mathrm{Br}$, reaction can occur via $\mathrm{H}$-atom abstraction or via addition to $\mathrm{C}=\mathrm{C}$ double bonds. The rate coefficient database for these reactions is extensive, though not quite as developed as for $\mathrm{OH}$. The $\mathrm{Cl}+\mathrm{VOC}$ reactions are generally less selective than the corresponding $\mathrm{OH}$ reactions. Despite this fact, these reactions (particularly those involving abstraction) are used extensively in laboratory studies as surrogates for $\mathrm{OH}$-initiated studies of VOC oxidation and/or for the production of specific alkyl or alkyl peroxy radicals.

An overview of structure-reactivity correlations for $\mathrm{Cl} / \mathrm{VOC}$ abstraction reactions has been presented by Poutsma. ${ }^{148}$ As summarized therein, group-additivity formulations (as described above for $\mathrm{OH}$ reactions) have been conducted by many groups, but typically for only mono-functional species and to subsets of the available data. Issues with applying the method to multifunctional species are discussed, with the effect of multiple substituent groups shown to be non-multiplicative. A more complex estimation method, based on a combination of Evans-Polanyi and Hammett parameters, was shown by Poutsma $^{148}$ to provide excellent predictive capability. Addition of $\mathrm{Cl}$-atoms to olefinic bonds are extremely rapid, exceeding $\approx 1 \times 10^{-10} \mathrm{~cm}^{3}$ molecule $\mathrm{e}^{-1} \mathrm{~s}^{-1}$ except for some halogen-substituted alkenes. Group-additivity structure-reactivity parameters for addition reactions have been determined by Teruel et al., ${ }^{149}$ although again based primarily on mono-functional species. Further work to unify these approaches based on a more complete data set, perhaps using Atkinson-style parameterizations, seems warranted.

\section{5.a.5 VOC + Br}

Reactions of Br-atoms with VOCs are of limited atmospheric importance, primarily exerting an influence in the marine boundary layer $(\mathrm{MBL}){ }^{2}$ These reactions are of particular significance in polar springtime MBLs, when surface snow/ice chemistry initiates $\mathrm{Br} / \mathrm{BrO}$ chemical cycles that deplete ozone to near-zero values in isolated instances. ${ }^{2,150} \mathrm{Br} / \mathrm{VOC}$ reactions can occur via abstraction or addition. ${ }^{2}$ For energetic reasons, abstraction reactions are slower than the corresponding $\mathrm{OH}$ or $\mathrm{Cl}$-atom abstractions; reactions are usually endothermic for alkanes, haloalkanes and ketones, and approach 
thermoneutrality for alcohols, ethers and aldehydes. Only a few rate coefficient measurements exist for each of these compound classes. ${ }^{2,151-153}$ Additions of Br-atom to unsaturated VOCs (alkenes and alkynes) are complex processes, as the Br-containing alkyl radical formed via addition typically decomposes to reactants on a time scale that is competitive with $\mathrm{O}_{2}$ addition to form a peroxy radical. ${ }^{2,153-155}$ The effective reaction rate coefficients thus generally possess complex temperature, pressure and $\mathrm{O}_{2}$ partial pressure dependencies. Measurable rate coefficients have been reported for reaction of Br-atoms with aromatics and furans. ${ }^{152,154}$ Due to the limited importance of $\mathrm{Br} / \mathrm{VOC}$ reactions in atmospheric chemistry, the complexity of the alkene/alkyne addition reactions, and the general paucity of data, SARs have not yet been developed.

\section{5.a.6 VOC $+\mathrm{O}\left({ }^{3} \mathrm{P}\right)$}

Reactions of ground state oxygen atoms, $\mathrm{O}\left({ }^{3} \mathrm{P}\right)$, are of interest in combustion, atmospheric chemistry, and astrochemistry. In the troposphere $\mathrm{O}\left({ }^{3} \mathrm{P}\right)$ atoms are removed rapidly via reaction with $\mathrm{O}_{2}$, concentrations of $\mathrm{O}\left({ }^{3} \mathrm{P}\right)$ atoms are thus orders of magnitude lower than the principal atmospheric oxidants $\left(\mathrm{OH}, \mathrm{NO}_{3}\right.$ and $\left.\mathrm{O}_{3}\right)$, and reaction with $\mathrm{O}\left({ }^{3} \mathrm{P}\right)$ is a negligible atmospheric fate of VOCs. ${ }^{2}$ However, reactions of VOCs with $\mathrm{O}\left({ }^{3} \mathrm{P}\right)$ can be significant in laboratory studies during UV irradiation of gas mixtures containing high concentrations of $\mathrm{NO}_{2}$, which can lead to much higher $\mathrm{O}\left({ }^{3} \mathrm{P}\right)$ concentrations than encountered in the troposphere. This may also be the case in plumes where high concentrations of $\mathrm{NO}_{2}$ and VOCs may both be present. Rate coefficients are available for reactions of $\mathrm{O}\left({ }^{3} \mathrm{P}\right)$ with a number of alkanes, alkenes, dienes, aromatics and oxygenates. ${ }^{156}$ Product studies have been reported in a relatively limited number of investigations. In general, the reactions of $\mathrm{O}\left({ }^{3} \mathrm{P}\right)$ with VOCs at room temperature proceed via similar mechanisms to those of $\mathrm{OH}$ ( $\mathrm{H}$ atom abstraction and/or electrophilic addition). Correlations between $\mathrm{O}\left({ }^{3} \mathrm{P}\right)$ and $\mathrm{OH}$ rate coefficients with alkenes and aromatics and a SAR for the reaction of $\mathrm{O}\left({ }^{3} \mathrm{P}\right)$ with alkanes are discussed in the literature. ${ }^{88}$

\section{5.a.7 VOC $+\mathrm{NO}_{2}$}

$\mathrm{NO}_{2}$ can react with unsaturated VOCs via addition and $\mathrm{H}$-atom abstraction, although these reactions are generally quite slow and of essentially no atmospheric significance. ${ }^{88,157,158}$ The reactions are most often encountered as interferences in chamber studies of OH / VOC chemistry. Reactions with monoalkenes are exceedingly slow, with values $\leq 10^{-20} \mathrm{~cm}^{3}$ molecule $\mathrm{s}^{-1} \cdot{ }^{88,157}$ Reactions with conjugated dienes are more rapid $\left(\approx 10^{-20}\right.$ to $10^{-17} \mathrm{~cm}^{3}$ molecule $\left.{ }^{-1} \mathrm{~s}^{-1}\right),{ }^{159}$ but still too slow to be of significance under typical (even polluted) ambient conditions. ${ }^{88,157,158}$ Though expected patterns of structure/reactivity are evident in the limited available data, ${ }^{158}$ and a basic SAR is available ${ }^{160}$ for alkylsubstituted alkenes and conjugated alkenes based on group additivity, no extensive SARs have yet been created for these reactions.

\section{5.b. Unimolecular $\mathrm{VOC}$ reactions}

The only organic compounds (other than radicals) that are known to undergo unimolecular reactions at non-negligible rates in the atmosphere are peroxynitrates, i.e., compounds with $-\mathrm{OONO}_{2}$ structures, which thermally decompose to form peroxy radicals and $\mathrm{NO}_{2}$. Peroxynitrates are not emitted directly but are formed by reactions of peroxy radials with $\mathrm{NO}_{2}$ and are often in equilibrium with the reactants, particularly at warmer temperatures near the Earth's surface. Decomposition rate coefficients have been measured and evaluated for several representative peroxynitrates. Atmospheric half-lives for decomposition at $298 \mathrm{~K}$ and $1 \mathrm{~atm}$ pressure are $\sim 0.5$ seconds for methyl peroxynitrate $(\sim 0.15 \mathrm{~s}$ at the high pressure limit $)^{90}$ and $\sim 0.5$ to $\sim 1$ hour for acyl peroxynitrates, $\mathrm{RC}(\mathrm{O}) \mathrm{OONO}_{2} \cdot{ }^{89}$ No SARs have been developed for peroxynitrate decompositions, though mechanism developers generally assume that the high-pressure rate coefficients for methyl peroxynitrate are representative of those for other alkyl 
peroxynitrates, using the high pressure rate coefficients for PAN $\left(\mathrm{R}=\mathrm{CH}_{3}\right)$ and $\mathrm{PPN}\left(\mathrm{R}=\mathrm{C}_{2} \mathrm{H}_{5}\right)$ for other acyl peroxy nitrates. However, halogenated alkyl peroxynitrates are considerably longer-lived than the standard alkyl peroxynitrates species, (e.g., $\mathrm{CF}_{2} \mathrm{ClOONO}_{2}$ stability is about 30 times that of $\mathrm{CH}_{3} \mathrm{O}_{2} \mathrm{NO}_{2}$ at $298 \mathrm{~K}) .{ }^{161}$ All of these decomposition reactions are highly temperature-dependent, and are significantly slower at the lower temperatures characteristic of the upper atmosphere or winter ozone episodes.

In terms of atmospheric impacts, the rates of decomposition of methyl and, by extension, other alkyl peroxy nitrates are too fast at temperatures encountered in the lower troposphere for them to build up to non-negligible concentrations. Their formation and decomposition can be ignored, despite the fact that their rates of formation in the presence of $\mathrm{NO}_{\mathrm{x}}$ and VOCs are relatively high. In contrast, the alkylperoxy nitrates do need to be considered at the lower temperature conditions of the middle to upper troposphere. Thus, while these species were neglected when modeling winter ozone episodes in Wyoming, where the temperature was around $265 \mathrm{~K},{ }^{162}$ there is now clear evidence for the presence of $\mathrm{CH}_{3} \mathrm{O}_{2} \mathrm{NO}_{2}$ in the upper troposphere ${ }^{163}$ at concentrations that are comparable to those of $\mathrm{NO}_{2}$.

In contrast to the alkylperoxy nitrates, PAN and the higher acyl peroxynitrates are stable even near 298 $\mathrm{K}$, and thus need to be considered under all atmospheric and environmental chamber conditions. The atmospheric lifetimes are longer than calculated using just the decomposition rate coefficient because they are in equilibrium with acyl peroxy radicals and $\mathrm{NO}_{2}$. These lifetimes are long enough for PAN and other acyl peroxynitrates to be transported over long distances and subsequently decompose to regenerate reactive $\mathrm{NO}_{\mathrm{x}}$, and thus serve as reservoir species that can impact ozone formation in multiday episodes. Thus, it is important to have appropriate rate coefficients and their temperature dependences for the formation and decomposition of these species included in regional models.

Relatively little is known about the effects of non-alkyl substituents on lifetimes of peroxynitrate species other than the effects of halogenation noted above, though the presence of $\mathrm{C}=\mathrm{C}$ bonds does not seem to have a large effect. ${ }^{89}$ Further work is needed to investigate whether non-alkyl peroxynitrates are formed to a sufficient extent and have sufficiently different decomposition rates that estimates for them need to be developed.

\section{5.c. Photolysis Reactions}

\section{5.c.1 Rate Coefficients and Actinic Flux}

Photo-dissociation and photo-tautomerization of atmospheric molecules by solar radiation plays a fundamental role in atmospheric chemistry. Many organic molecules absorb solar radiation at wavelengths $\lambda$ of sufficient energy to break or rearrange some bonds, leading not only to their direct degradation but also to the production of radical photo-fragments that can significantly affect daytime atmospheric reactivity. Photolysis or photo-dissociation is the general class of reactions R1 described as:

$$
\mathrm{ABC}+h v \rightarrow \mathrm{AB}+\mathrm{C}
$$

$\mathrm{R} 1$

For some molecules, photo-induced intramolecular rearrangement is also possible, e.g. phototautomerization of acetaldehyde to vinyl alcohol. ${ }^{164}$ The rate coefficients for photochemical reactions are quantified by the first-order rate coefficient $j$, which is calculated from equation E1:

$$
j=\int \sigma(\lambda, T) \Phi(\lambda, T, P) F(\lambda) d \lambda
$$

as given by Finlayson-Pitts, ${ }^{3}$ where $\mathrm{F}(\lambda)$ is the spectral actinic flux at wavelength $\lambda, \sigma(\lambda, T)$ is the molecular absorption cross section and $\Phi_{i}(\lambda, T)$ is the quantum yield of various possible dissociation or 
rearrangement channels $i$ (e.g., in illustrative reaction $\mathrm{R} 1$, atom ' $\mathrm{C}$ ' as the leaving moiety can be $\mathrm{A}, \mathrm{B}$, or C). Both $\sigma$ and $\phi$ are typically wavelength dependent and can also be temperature $(T)$ and pressure $(P)$ dependent.

The absorption cross-sections $\sigma$ and quantum yields $\Phi$ need to be specified as part of the mechanisms, being specific to the photo-process. The spectral actinic flux, on the other hand, is a property of the environment being modeled ${ }^{165-167}$ and is independent of the chemical mechanism employed. A pertinent observation is that the transmission through stratospheric ozone varies by many orders of magnitude over a narrow wavelength range (ca. 295-320 nm), implying the need for comparatively high spectral resolution in this wavelength range. Chemical mechanisms generally compute $j$ by one of three ways: (i) direct convolution (see equation E1) of the actinic flux with the $\sigma$ and $\Phi$ for the molecule of interest as obtained from laboratory measurements, (ii) assign the $j$ for a reaction with unknown characteristics to the $j$ from another (surrogate) known reaction, or (iii) use SARs for estimating $\sigma$ and $\Phi$, which is the focus here.

\section{5.c.2 Absorption Cross Sections}

Absorption cross sections or spectra are known for many - though far from all - organic molecules of atmospheric interest. Most emitted hydrocarbons do not absorb at tropospheric wavelengths. Thus here we are dealing mostly with the partially oxidized intermediates, which themselves can become a large fraction of reactive species (e.g. as measured by $\mathrm{OH}$ reactivity) as a polluted air parcel ages, where the contribution of photolysis of oxidized intermediates becomes the major source of radicals (Figure 1).

Simple moieties (chromophores) that absorb at tropospheric UV wavelengths include carbonyls $(-\mathrm{C}(=\mathrm{O})-$ and $-\mathrm{CHO})$, nitrates $\left(-\mathrm{ONO}_{2}\right)$, peroxides $(-\mathrm{OOH})$, and iodo- and bromo-substituted molecules; while simple alcohols $(-\mathrm{OH})$, carboxylic acids $(-\mathrm{C}(=\mathrm{O}) \mathrm{OH})$, and esters $(-\mathrm{C}(=\mathrm{O}) \mathrm{O}-)$ are not expected to absorb at tropospheric wavelengths. Absorption spectra are available for many molecules containing a single chromophore (e.g. simple ketones, aldehydes, organic peroxides and nitrates), but data are much sparser for multifunctional molecules, i.e. containing multiple chromophores or a chromophore and other functionalities, or molecules that also contain double bonds. Different spectra may be expected depending on the nature and location of the substitutions (e.g. multiple chromophores, conjugation, etc.). For molecules containing well-separated chromophores, some additivity rules have been explored but are not fully developed. ${ }^{168,169}$ Substitutions at the important $\alpha$ position have been explored for relatively few molecules and remain an important uncertainty.

Compilations of absorption cross sections are available. Both the IUPAC Task Group on Atmospheric Chemical Kinetic Data Evaluation ${ }^{90}$ and the NASA JPL Chemical Kinetics and Photochemical Data for Use in Atmospheric Studies ${ }^{91}$ panels provide evaluated compilations of kinetic and photochemical data, including laboratory measured cross sections for a range of atmospherically important species. Other useful databases of absorption cross sections include the comprehensive Mainz Spectral Atlas (http://satellite.mpic.de/spectral_atlas) and the thorough recommendations given by the Calvert et al. reviews on the mechanisms of atmospheric oxidation of alkenes, aromatics, alkanes and oxygenates. ${ }^{2,19,87-89}$

\section{5.c.3. Quantum yields}

Quantum yields are inherently related to the energy of incident photons relative to the strength of the bonds in target molecules. Thus, quantum yields at visible wavelengths tend to be near zero, and increase toward shorter, more energetic wavelengths. Near threshold, thermal vibration and rotation can contribute to this increase. The possibility of multiple product channels means that quantum yield 
values for individual channels can be less than one, even at the shortest wavelength. For many molecules (e.g. carbonyls) laboratory studies show that quantum yields decrease with increasing pressure (especially near threshold), implying substantial collisional quenching. This pressure effect is understood by considering the photolysis reaction R1 as composed of three parts,
$\mathrm{ABC}+h v \rightarrow \mathrm{ABC}^{*}$ (excited state formation)
$\mathrm{R} 2$
$\mathrm{ABC}^{*}+\mathrm{M} \rightarrow \mathrm{ABC}$ (quenching)
R3
$\mathrm{ABC}^{*} \rightarrow \mathrm{AB}+\mathrm{C}$
(fragmentation)
$\mathrm{R} 4$

Assuming steady state for the excited molecule ABC* gives the well-known Stern-Volmer expression, in which the reciprocal of the quantum yield increases linearly with pressure $[\mathrm{M}]$,

$$
1 / \Phi=1+\left(k_{3} / k_{4}\right)[\mathrm{M}] \quad \text { E2 }
$$

where $k_{3}$ and $k_{4}$ are the rate coefficients for R3 and R4, respectively. Temperature dependences of quantum yields are also known to exist.

Even compared to the experimental literature database for cross sections, coverage is poor for quantum yield data, especially for wavelength-dependent measurements. Currently, there are no SARs specifically available to predict quantum yields of organic photolysis reactions. In cases where quantum yields of 0 or 1 are not obvious choices, methods are needed to predict the relative probabilities of multiple dissociation channels and the influence of environmental factors such as temperature and pressure. A lack of detailed quantum yield information leads to inaccurate product yields and missing product channels (radicals, non-radical channels and photo-induced intramolecular rearrangement), which will impact the accuracy of the chemical mechanisms.

Compilations of quantum yields are available from the same sources as listed above for the absorption cross sections, although quantum yield data are much sparser

\section{5.d. Reactions of reactive intermediates}

As discussed in Section 2.a, the initial reactions of the VOCs form various types of radicals, whose multiple possible reactions cause much of the complexity and uncertainty in atmospheric mechanisms. Although a variety of types of radicals can be formed (see Figure 2), for the purpose of this discussion we will consider carbon-centered radicals, peroxy radicals, alkoxy radicals, and Criegee intermediates (carbonyl oxides, sometimes called Criegee biradicals), which are the most important examples. In some cases, e.g., for most carbon-centered radicals and certain rapidly decomposing radicals there is only one dominant fate so quantitative estimates of rate coefficients are not important for atmospheric mechanisms. However, peroxy radicals have a number of competing bimolecular reactions and some may also have competitive unimolecular reactions. Alkoxy radicals likewise have a number of competing reactions whose relative importances are estimated to be highly variable depending on the radical. Reliable quantitative SARs for these reactive intermediates are necessary to determine the relative importance of these competing processes and also to determine which reactions are dominant or negligible.

\section{5.d.1 Carbon-centered radicals}

Carbon-centered radicals include alkyl $\left(\mathrm{R}^{\bullet}\right)$, carbonyl $\left(\mathrm{RC}^{\bullet}(\mathrm{O})\right)$ and vinyl $\left(=\mathrm{C}^{\bullet}\right)$ radicals. Vibrationally excited carbon-centered radicals can be formed when $\mathrm{OH}$ or another radical adds to double bonds or when these radicals are formed in photolysis reactions. Regardless of initial excitation, the major fate for most such radicals is reaction with $\mathrm{O}_{2}$, as the lifetime of carbon-centered radicals with respect to reaction with $\mathrm{O}_{2}$ is of the order of 10-100 ns, owing to a combination of high rate coefficients and high $\mathrm{O}_{2}$ concentration. Most atmospheric kinetic models do not include carbon-centered radicals explicitly, 
but rather represent them by formation of their products. Although most react to form the corresponding peroxy radical, those with labile hydrogens whose removal would form a stable product, such as $\alpha$-hydroxy or formyl radicals, react instead by $\mathrm{H}$-abstraction forming $\mathrm{HO}_{2}$ and an oxygenated product, either as a concerted process or after formation of a short-lived peroxy radical. For example for very-high NOx conditions it was reported ${ }^{170}$ that reactions of the intermediate $>\mathrm{C}(\mathrm{OH}) \mathrm{OO}{ }^{\bullet}$ radical with $\mathrm{NO}$ can lead to the formation of $\mathrm{NO}_{2}$ and a carboxylic acid. $\mathrm{H}$-abstraction also operates for $\mathrm{OH}-$ aromatic adducts, but $\mathrm{O}_{2}$ addition and decomposition reactions are also thought to occur. ${ }^{19}$ In contrast, vinylic radicals add $\mathrm{O}_{2}$ across the double bond to give a carbonyl compound and a carbonyl radical. ${ }^{\text {e.g, } 171}$

However, certain carbon-centered radicals decompose sufficiently rapidly that decomposition competes with $\mathrm{O}_{2}$ reaction, in some cases even for thermalized radicals. Radicals of the type $>\mathrm{C}^{\circ} \mathrm{OX}$ can rapidly form $>\mathrm{C}=\mathrm{O}+\mathrm{X}^{\bullet}$, where $\mathrm{X}=\mathrm{OH}, \mathrm{OR}, \mathrm{NO}_{2}$, or $\mathrm{ONO}_{2}$, in decompositions that are exothermic and not expected to have large entropy or activation barriers. Substituted carbonyl radicals, $\mathrm{XC}(\mathrm{O})^{\bullet}$, may also decompose to form $\mathrm{X}^{\bullet}+\mathrm{CO}$ if the $\mathrm{X}-\mathrm{CO}$ bond is sufficiently weak or the radical is sufficiently excited. For example, for $-\mathrm{C}(\mathrm{O}){ }^{172}$ and $-\mathrm{Cl}^{173}$ substitutions, the decomposition has been shown to be fast, and calculations ${ }^{174}$ also suggest fast decomposition reactions for $-\mathrm{CCl}_{3}$ and $-\mathrm{C}\left(\mathrm{CH}_{3}\right)_{2} \mathrm{OH}$ substituents. Comprehensive SARs do not exist for such reactions, though rate coefficients have been theoretically calculated for several examples ${ }^{174}$.

Carbon-centered radicals with peroxide substituents may also undergo cyclization, where the weak O$\mathrm{O}$ bond breaks and reacts with the radical center, forming a cyclic ether and a radical co-product. For "QOOH" radicals, important in combustion systems and in atmospheric HOM formation, Curran et $\mathrm{al}^{175}$ estimated rate coefficients for cyclization and showed that some may be sufficiently fast to possibly compete with $\mathrm{O}_{2}$ addition under atmospheric conditions.

Although the role of the cyclization of unsaturated thermalized carbon-centered radicals is uncertain, there is experimental evidence that vibrationally excited carbon-centered radicals formed from the addition of $\mathrm{OH}$ to double bonds undergo cyclization reactions forming epoxides or other products. Evidence for this has been reported in studies of reactions of $\mathrm{OH}$ with unsaturated hydroperoxides ${ }^{\text {e.g, }} 176$ and unsaturated PAN compounds ${ }^{\text {e.g, } 177}$ formed in the reactions of isoprene. However, comprehensive SARs do not exist for cyclization reactions of either stabilized or excited radicals.

Carbon-centered radicals adjacent to a 3- or 4-membered ring may undergo ring opening, forming a double bond and another carbon radical center. Experimental and theoretical evidence of this is seen in product studies of the reactions of $\mathrm{OH}$ with terpenes and terpene products where the $\mathrm{OH}$ addition forms carbon-centered radicals adjacent to a 4-membered ring. ${ }^{170,178,179}$ Vereecken and Peeters ${ }^{179}$ calculated that ring opening of the excited $\mathrm{OH}+\beta$-pinene adduct occurs $\sim 70 \%$ of the time, with the remaining radicals being collisionally stabilized. Ring opening of radicals adjacent to 5-membered or larger rings are endothermic and therefore not important under atmospheric conditions.

\section{5.d.2 Alkylperoxy radicals}

Under atmospheric conditions, most alkylperoxy radicals react through bimolecular reactions with NO, $\mathrm{RO}_{2}$ or $\mathrm{HO}_{2}$, but a few have unimolecular reactions fast enough to be non-negligible or even dominate over the competing bimolecular reactions. ${ }^{180-182}$ Recent estimates indicate that the rates of multiple loss processes can be competitive in many cases, with product formation depending on rate coefficients as well as atmospheric co-reactant concentrations; isoprene oxidation is an important example. ${ }^{183,184}$ Reactions of several $\mathrm{RO}_{2}$ are currently insufficiently known and better quantification is needed.

The reaction of $\mathrm{RO}_{2}$ with $\mathrm{NO}$ yields either alkoxy radicals $+\mathrm{NO}_{2}$, or nitrates, $\mathrm{RONO}_{2}$. As nitrate formation is a significant radical loss process, easily exceeding $20 \%$ of the mass flux of organics 
oxidation, the nitrate yields are important inputs into mechanisms. This reaction is typically in the falloff regime, making the nitrate yield temperature- and pressure-dependent. While SARs exist to predict nitrate yields for linear and branched alkylperoxy radicals, ${ }^{36}$ little is known about the influence of heterosubstitution, cycles, unsaturation, or aromaticity on the nitrate yield. Nitrate yield SARs need to be extended to apply to all types of peroxy radicals. This includes acyl peroxy radicals, where nitrate formation has been assumed to be minor but cannot necessarily be ruled out. Importantly, $\mathrm{RCO}_{2}+\mathrm{NO}_{2}$ reactions lead to the formation of short-lived peroxy-nitrate reservoir species that, depending on temperature and pressure, mostly re-form reactants upon decomposition (see Section 5.c).

The reaction of $\mathrm{RO}_{2}$ with $\mathrm{HO}_{2}$ can yield either $\mathrm{ROOH}+\mathrm{O}_{2}, \mathrm{RO}+\mathrm{O}_{2}+\mathrm{OH}$, or $\mathrm{ROH}+\mathrm{O}_{3}$, though hydroperoxide formation, $\mathrm{ROOH}$, is believed to be the major process for most alkyl peroxy radicals. Recent measurements ${ }^{185,186}$ show that all three routes can be important for acyl peroxy radicals, $\mathrm{RC}(\mathrm{O}) \mathrm{O}_{2}$, with branching ratios derived for smaller members of the series. Non-hydroperoxide routes appear important as well in the case of peroxy radicals with carbonyl groups located in $\alpha$-position to the peroxy function, although this process too has only been investigated for a few smaller $\mathrm{RO}_{2}$ species. ${ }^{187,188}$ Some SARs exist for the total rate constants for $\mathrm{RO}_{2}+\mathrm{HO}_{2}$ reactions, ${ }^{189-191}$ but none estimate the contributions for the $\mathrm{OH}$ - and $\mathrm{O}_{3}$-forming channels.

The reaction of $\mathrm{RO}_{2}+\mathrm{RO}_{2}$ is a complex reaction class due to the large number of reactant permutations needed in the models. All models treat this class in an approximate manner, typically by assuming a reactive pool of $\mathrm{RO}_{2}$ radicals rather than explicitly speciated $\mathrm{RO}_{2}$ co-reactants; treatment of the $\mathrm{RO}_{2}$ pool and estimation of rates differ between implementations. ${ }^{5,8,36}$ Under atmospheric conditions, this works reasonably well, as $\mathrm{CH}_{3} \mathrm{OO}$ is by far the most abundant peroxy radical and drives the $\mathrm{RO}_{2}$ crossreactions. For modeling studies under different conditions, e.g. chamber studies that oxidize a single organic compound, defining the $\mathrm{RO}_{2}$ reaction pool is less straightforward, and could cause different product channel contributions. Recent measurements on HOM (highly oxidized organic molecules) formation in the context of aerosol formation suggest that the $\mathrm{RO}_{2}$ intermediates can also form dimers and polymers, though the exact reaction mechanism for chain elongation is not currently known. ${ }^{21,179,192}$ Current research on low-volatility compounds in SOA formation could benefit from a detailed description of $\mathrm{RO}_{2}+\mathrm{RO}_{2}$ reactions, both by a more nuanced description of the $\mathrm{RO}_{2}$ pool, and via further study of product yields from these reactions.

There is some evidence from $\beta$-pinene oxidation modeling that ring closure reactions in unsaturated $\mathrm{RO}_{2}$ radicals can strongly affect the chemistry and radical propagation chain. ${ }^{179,193,194}$ Oxidation of aromatic compounds also has a large flux through bicyclic compounds formed from $\mathrm{RO}_{2}$ ring-closure reactions. ${ }^{195,196}$ For neither reaction is a SAR available. It is currently unclear whether such $\mathrm{RO}_{2}$ ring closure reactions are a common reaction class, or merely a channel active for only aromatics and a handful of other VOCs.

$\mathrm{H}$-migration in $\mathrm{RO}_{2}$ radicals was recently shown to be critical to describe low- $\mathrm{NO}_{\mathrm{x}} \mathrm{OH}$-regeneration processes in terpenoid isomerization, and for the formation of HOMs for a variety of reactant classes. $^{20,182}$ Some SARs are available, but these are not extensive enough to treat the highlyfunctionalized compounds formed in HOM formation. Since many of these reactions are estimated to be competitive with bimolecular reactions, accuracy for such SARs is critical to obtaining proper yields, with better estimation of aerosol yields. ${ }^{197}$ This area has clear synergies with efforts in lowtemperature combustion, where similar reaction pathways ${ }^{181,198}$ were shown to be important for radical chain branching.

Once formed, most $\mathrm{RO}_{2}$ radicals are sufficiently long-lived that they will participate in the bimolecular reactions described above. There are two notable exceptions to this: 1.) Recent work suggested that the reaction of resonance-stabilized allyl radicals with $\mathrm{O}_{2}$, forming $\beta$-vinyl-alkylperoxy radicals, can be 
treated as reversible. Specifically, $\mathrm{RO}_{2}$ intermediates from allyl-stabilized alkyl radicals formed in the isoprene oxidation were shown ${ }^{199}$ to redissociate, and thus contribute to the re-equilibration of the various $\mathrm{RO}_{2}$ adducts as they are depleted through various isomer-specific channels. Aromatic compounds likewise exhibit re-dissociation of alkylperoxy radicals after the reaction initiation with $\mathrm{OH}$, channeling aromatic oxidation through channels that favor ortho-substitution. ${ }^{200}$ There is as yet no $\mathrm{SAR}$ available that is able to describe this $\mathrm{O}_{2}$-addition/re-elimination, hampering studies on $\mathrm{OH}$ regeneration and aromatic oxidation. 2.) Where the resulting peroxy radical contains a labile geminal bond (such as the $\mathrm{C}-\mathrm{I}$ bond in $\mathrm{CH}_{2} \mathrm{IOO}$ ), excess energy from the addition reaction may be sufficient for bond scission leading to the formation of stabilized Criegee intermediates; ${ }^{201}$ No SAR is available to predict these reactions.

\section{5.d.3 Alkoxy radicals}

Alkoxy radicals have a number of competing reaction pathways, and in many cases no single pathway necessarily dominates, making quantitative estimates or rate coefficients important. By and large, alkoxy radical decomposition or $\mathrm{H}$-abstraction by $\mathrm{O}_{2}$ are well-understood processes, and several SARs $^{97,103,105,190,202-207}$ are available that can guide model development. However, extension of these SARs to multifunctional compounds would be beneficial, especially to verify whether long-range interactions should be considered. Less is known about H-migration in alkoxy radicals, an important channel that has also recently been implied in sequential oxidation steps in HOM formation. Some SARs are available, ${ }^{103,104,106,202-204,208,209}$ but as H-migration is clearly dependent on substitution and long-range interaction, a significant effort towards extending the SARs is necessary. H-atom elimination was shown to be important in some ether-alkoxy radicals, ${ }^{210-213}$ no estimation methods are available for this reaction class. In addition, no estimation methods are available for "ester rearrangement" reactions, which involve $\mathrm{H}$ shifts to a carbonyl group and formation of an acid and carbonyl radical, ${ }^{214,215}$ though rate coefficients relative to other alkoxy reactions can be estimated from

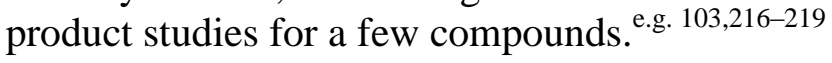

Reaction of a typical alkylperoxy radical with $\mathrm{NO}$, forming an alkoxy radical and $\mathrm{NO}_{2}$, is exothermic by $15-20 \mathrm{kcal} \mathrm{mol}^{-1}$ and much of the energy is imparted to the alkoxy radical product. ${ }^{2}$ When an alkoxy radical has a low energy barrier to unimolecular decomposition, a significant fraction of the nascent alkoxy radicals have then sufficient energy to overcome the barrier, allowing for "prompt", nonthermal decomposition. The remaining fraction of the alkoxy radicals is thermalized by collisions with the bath gas. While it has been shown that chemical activation in the exothermic $\mathrm{RO}_{2}+\mathrm{NO}$ reaction plays an important role in the atmospheric fate of some alkoxy radicals, the general importance of chemical activation in the gas-phase atmospheric chemistry of alkoxy radicals remains unclear, and could benefit from more extensive experimental and theoretical datasets. Data is particularly needed for halogenated and oxygenated alkoxy radicals. Formation of alkoxy radicals from $\mathrm{RO}_{2}+\mathrm{RO}_{2}$ reactions is less exothermic, and thus less influenced by chemical activation.

Ring closure in unsaturated alkoxy radicals has been reported ${ }^{179}$ to affect the chemistry for some VOCs, but it remains unclear whether this reaction class deserves a high priority in kinetic model development. Targeted quantum chemical calculations on specific RO radicals formed in the current atmospheric mechanisms could determine whether this reaction class can be competitive.

\section{5.d.4 Criegee intermediates}

Several sources of carbonyl oxides (Criegee intermediates, CI) are active in the atmosphere. The largest of these is the ozonolysis of unsaturated VOCs such as the terpenoids that make up most of the nonmethane organic compounds emitted to the atmosphere. Other potential sources of CI include the reaction of $\mathrm{O}_{2}$ with carbenes formed in photolysis reactions, ${ }^{220}$ the oxidation of iodinated 
compounds $^{221,222}$ or dimethyl sulfoxide ${ }^{223}$ emitted from the oceans, and lightning discharge ${ }^{224}$ on atmospheric $\mathrm{CH}_{4}$. In determining the fate of $\mathrm{CI}$ in the atmosphere, a distinction must be made between excited and stabilized CI (SCI), as CI can be formed with a wide range of internal energies, ranging from 0 to nearly $\sim 100 \mathrm{kcal} \mathrm{mol}^{-1} ;{ }^{128,129}$ the difference in internal energy imparted by the formation reaction will strongly affect their chemistry. ${ }^{129,225-228}$

Excited CI have a high energy content, with lifetimes that are too short to have an appreciable chance of undergoing bimolecular reactions under atmospheric conditions. These CI undergo prompt unimolecular reactions, with some $\mathrm{CI}$ efficiently forming $\mathrm{OH}$ and other radical species via isomerization through a vinylhydroperoxide intermediate, ${ }^{129}$ or they become stabilized by energy loss in collisions with air molecules. Formulating a SAR for excited CI is difficult, since each formation reaction imparts a different energy distribution to the $\mathrm{CI},{ }^{227,229,230}$ which in turn affects the product yield distribution through the different unimolecular reactions available, as well as changing the fraction of $\mathrm{CI}$ that will be collisionally thermalized. Indeed, even the formation of the same CI, e.g. $\mathrm{CH}_{2} \mathrm{OO}$, from similar molecules such a set of $\mathrm{C}_{10} \mathrm{H}_{16}$ monoterpenes, will impart a different $\mathrm{CI}$ energy distribution (i.e. different ratio of thermalized versus chemically activated $\mathrm{CI}$ ), and hence result in a different chemical fate of the CI. Temperature and pressure will also alter this energy distribution. Typically, due to the fast reactions of excited CI, their product formation is lumped into the formation reaction, where each reaction has somewhat different yields. SARs exist for the total $\mathrm{OH}$ yields from ozonolysis reactions; ${ }^{6,129}$ these are based on the structure of the parent alkene and assume that $\mathrm{OH}$ is being formed predominantly via a vinylhydroperoxide intermediate. Large gaps remain in our knowledge on the fate of excited CI, and the relative yield of excited versus stabilized CI. This lack of knowledge is exacerbated by experimental difficulties, where it is not always easy to distinguish between products formed from excited or stabilized CI, or to isolate the impact of secondary chemistry of the CI involved; complementary theoretical studies may be a significant help.

Stabilized CI can be formed either directly in the source reaction, e.g. an ozonolysis reaction, or through thermalization of excited CI, where the collisional energy loss process implies a pressure and bath gas dependence on their yield. Once formed, the fate of SCI is not determined by their source reaction. The yields of SCI are poorly constrained, though some predictive correlations have been proposed, relating measured SCI yields to the structure of the parent alkene ${ }^{6}$ or the measured total ozonolysis $\mathrm{OH}$ yield. ${ }^{129}$ The speciation and stereoconformation of the different SCI that can be formed in a single formation reaction has likewise only been documented for a handful of ozonolysis

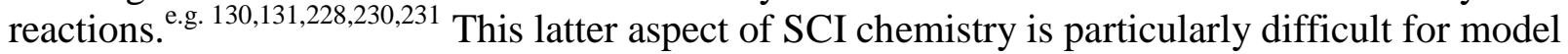
developers, as SCI rate coefficients can vary by many orders of magnitude, even across CI stereoisomers. ${ }^{232} \mathrm{SCI}$ have a longer lifetime than excited CI, of the order of microseconds to minutes, and can therefore undergo bimolecular reactions in competition with unimolecular reactions. SCI can act as an oxidant, where reaction with water vapor (i.e. $\mathrm{H}_{2} \mathrm{O}$ and $\left.\left(\mathrm{H}_{2} \mathrm{O}\right)_{2}\right)$ is the dominant bimolecular loss process in the atmosphere. ${ }^{232}$ Literature studies over the last decade have described the reactivity of SCI, mostly focusing research efforts on the smallest SCIs, i.e. H-atom- and methyl-substituted SCI. Significantly less information is available on the larger, more structurally diverse SCI formed from terpenoids. Very recently, an extensive theoretical study ${ }^{232}$ made SARs available for the unimolecular reactions of SCI, and their reaction with water vapor, incorporating several of the functionalities present in primary emitted VOCs and their main first-generation products. These and other results suggest that the concentration of SCI in the atmosphere is very low, $10^{3}$ to $10^{5}$ molecule $\mathrm{cm}^{-3},{ }^{232-235}$ with a limited impact on atmospheric processes, but the accuracy of the predictions still does not allow for a definitive resolution of the importance of SCI chemistry in the atmosphere. The important contribution of unimolecular loss processes for SCI is the generation of a large quantity of oxygenates and radicals whose chemistry is currently not included in the atmospheric models. 
Extensive experimental and theoretical information ${ }^{90,128,222,232,236-243}$ is available on bimolecular reactions of SCI, including co-reactants $\mathrm{H}_{2} \mathrm{O},\left(\mathrm{H}_{2} \mathrm{O}\right)_{2}$, organic and inorganic acids, $\mathrm{SO}_{2}, \mathrm{NO}_{2}, \mathrm{ROH}$, $\mathrm{ROOH}, \mathrm{HO}_{2}$ and $\mathrm{RO}_{2}$ radicals, and $\mathrm{O}_{3}$. These could have an impact on SCI chemistry either in the atmosphere or in the laboratory and chamber experiments from which much of our knowledge of the ozonolysis reaction is derived. SCI photolysis could likewise affect SCI concentration. ${ }^{244,245}$ The reactivity trends for the many SCI in these loss processes has not been elucidated yet, though it has become clear that different conformers of the same SCI can have very different reactivities. For many co-reactants, the rate coefficients span only a limited range across all SCI examined thus far, or exhibit correlations to molecular properties, e.g. gas-phase acidity, ${ }^{246}$ easing the development of SARs. The fates of the products from these reactions are typically not well known, including the fate of hydroxyhydroperoxides formed from the atmospherically important SCI + water reaction. Careful inclusion of SCI products, however, is essential in many situations; e.g. CI are known to be non-photolytic sources of $\mathrm{HO}_{\mathrm{x}}$ and $\mathrm{RO}_{2}$ radicals, and might thus affect radical chemistry during the night time.

For CI formed in the atmosphere, i.e. mostly from large terpenoids, it thus often remains an open question what rate coefficients to use, which products are formed, how their reaction products should be treated, and whether this product formation can be lumped into the CI formation reaction or if explicit modeling of SCI chemistry is necessary. Furthermore, the CI/SCI chemistry is highly dependent on their (stereo-specific) structure, requiring explicit Criegee intermediate speciation, which is currently difficult. Secondary ozonolysis of unsaturated products formed from primary emitted VOCs is also not adequately described, a significant knowledge gap given the contribution of polyunsaturated compounds to atmospheric emissions. Irrespective of how Criegee intermediate chemistry will ultimately be included in kinetic models, its importance is clear, given the large mass flux of alkenes towards SCI, and their ability of adding functionalities and increase molecular mass in ways that distinguish it from other reactants, resulting in large changes in volatility ${ }^{21}$ in comparatively few reaction steps. 


\section{SARs for thermochemistry}

Thermochemistry estimations are often used as inputs to kinetics SARs. Some kinetic SARs link activation energy to the enthalpy of reactions and others may need thermochemistry to get reverse rate coefficients when reversibility is important, or if it is easier to estimate the rate coefficient in the reverse direction. In these cases, accurate values of enthalpy, entropy and heat capacity are essential in getting accurate kinetics. Compared to combustion modeling, thermochemistry is often less directly used in atmospheric applications, though it is often used as a basis for screening proposed mechanisms, reactivity trends, SARs, or chemical understanding. The currently best thermochemical data is available in the Active Thermochemical Tables (ATcT ${ }^{24-249}$ ), which generate an internally consistent network of interconnected thermochemical predictions. The underlying data includes experimental, but also high-level theoretical data, providing input data that can be hard to obtain experimentally.

Group additivity is by far the most common approach to estimate thermochemistry. This method identifies various types of groups within a molecule and assigns each group thermochemical values. Corrections are then applied to account for longer distance interactions. The sum of all the group values and corrections gives a thermochemistry estimate for the molecule, with adjustments made for rotational symmetry and optical isomers.

In the late 1950's through the 1970's, Benson et al. ${ }^{250-253}$ developed the group additivity method for estimation of molecular thermochemical properties via additivity of group properties. The estimation procedures of the Group Additivity method were fully described in Benson's book on Thermochemical Kinetics, ${ }^{250}$ in which their calculated group values for hydrocarbons, oxygen-containing compounds, nitrogen-containing compounds, halogen-containing compounds, sulfur-containing compounds, organometallic compounds, along with some organo-phosphorus groups and organo-boron groups were developed based on the work by Benson et al. ${ }^{252,253}$ There have been a number of updates and additions to the group additivity values since the original groups were derived, ${ }^{82,254-263}$ and work in this area is continuing. There are also several, valuable calculation sets and critical evaluation reviews on thermochemical properties that provide extensive listings of reference values for aliphatic, oxygenated, sulfur- and nitrogen-bearing organic compounds and radicals. ${ }^{264-269}$

Group additivity's accuracy decreases when these groups and corrections have non-linear interactions. This can occur when two functional groups are on adjacent carbons or a molecule has a conformer that allows distant functional groups to form a hydrogen bond. Since group additivity is based on linear contributions, these interactions create a source of error. One way to get around potential error is to create separate supergroups, like oxygenated rings, which encompass multiple interacting groups or corrections. $^{270}$ This eliminates the error for the interaction between two functional groups, but the sheer number of potential non-linear interactions between groups makes estimation of all possible multifunctional molecules a challenge. There are few high-accuracy data (either theoretical or experimental) on peroxy radical species, polycyclic compounds including heteroatoms, and unsaturated or halogenated oxygenates, so the group additivity estimates for those molecules and the corresponding radicals are significantly uncertain.

Another challenge with group additivity occurs from different implementations in various software. ${ }^{271-}$ ${ }^{273}$ In addition to standard groups described by Benson, most software has added new groups and/or modified the original values given by Benson. Even when different software identifies the same groups in a molecule, differences result in the exact value of estimation. When assessing three group additivity packages, THERM, NIST, and THERGAS, different thermo values resulted even when the same groups were found. ${ }^{274}$ A more thorough comparison of different additivity implementations and a standardized method to refit group additivity parameters would be helpful in ensuring additivity values are both accurate, up to date and consistent. 
Both the SAPRC and GECKO-A atmospheric mechanism generation systems have used group additivity thermochemical estimates to support some SARs or mechanism assignments. The generated mechanisms included formation of compounds or radicals containing structures for which thermochemical group values had to be estimated by the system developer. A comparison of thermochemical group values used by SAPRC and GECKO-A shows that some of these estimates are significantly different, indicating that there is a need to review and extend these group additivity estimates. 


\section{Summary and outlook}

In this perspective, we have discussed the work needed for the development of more accurate and predictive detailed mechanisms that are consistent with the state of the science and current kinetic data and theories. The focus has been on the status of the development of the many SARs needed to make estimates where no data are available. As discussed above, one or more SARs exist for many of the reaction classes in the atmosphere. However, we also find there is a clear need for extending and improving existing SARs, as none are able to fully cover the needs of modern atmospheric model development. Elementary reactions of mono-functional compounds are well-described, but predictions for multi-step reactions, including chemically activated reactions, are often poor. Temperature- and pressure-dependence is not available in all cases. Multi-functionalized compounds are a particular problem, hampering our understanding of HOM formation, aerosol and particulate matter growth and aging, and the health and climate effects related to these. An analysis of the multi-functionalization included in automatically generated mechanisms shows which cross-functionalizations are most important, which can guide SAR development.

It is evident that updating the chemical atmospheric kinetic models to resolve $21^{\text {st }}$ century research questions will require a Herculean effort, which is only feasible by a community-driven collaboration. To address this, the authors of this perspective have recently formed a panel to address a subset of the problems highlighted here, hoping to provide a nucleus from which steady progress can be achieved and in time provide a solid basis for modern atmospheric modeling. Efforts on expanding the data compilations build upon existing data repositories such as IUPAC, JPL/NASA, the NIST Kinetics database, and review literature, or collaborate with parallel efforts such as the EUROCHAMP-2020 and MAGNIFY initiatives. For theoretical work, no extensive pre-existing data sets exist for atmospheric chemistry; the initial efforts of the SAR evaluation panel will thus focus on developing the necessary data structures and information, and the gathering of an initial set of data on a limited range of reactions to co-develop appropriate data entry, exchange, and retrieval tools. The data gathering is initially focused on gas phase reactions, but in time, however, the scope should expand towards information on liquid phase, gas-surface interface, and particulate chemistry.

A central working theme of this SAR evaluation panel is the selection, evaluation and implementation of SARs. For each of the relevant reaction classes, literature surveys will tabulate the available SARs, and analyze their scope of application. Evaluation of the SAR quality is a key aspect in this effort, and will build upon the data collected as described above. The critical review of the available SARs will lead to recommendation as to their use, allow for reference implementations, and identify the areas where current SARs are lacking or are not available. The data collection and SAR evaluation will also support efforts to improve and extend the SARs, and to create new SARs where necessary. Again, the initial focus will be on the most critical gas phase reactions, but gradually other aspects of atmospheric chemistry will be included. The need to understand air quality and climate change better, places increasing demands on the predictive capabilities of atmospheric models, and compared to earlier challenges often involve more, and more subtle and complex chemistry. Only a community-wide effort, based on open-access contribution, feedback, and support from many branches in the chemical and atmospheric sciences can hope to meet these challenges in a long-term sustainable way. 


\section{Acknowledgements}

We acknowledge the Coordinating Research Council's Atmospheric Impacts Committee who gave the authors their support and monitored this study.

The National Center for Atmospheric Research is operated by the University Corporation for Atmospheric Research, under the sponsorship of the National Science Foundation.

Bernard Aumont and Andrew Rickard acknowledge support from the Mechanisms for Atmospheric chemistry: GeneratioN, Interpretation and FidelitY - MAGNIFY project through funding from the French National Research Agency (ANR, via grant ANR-14-CE01-0010) and the UK Natural Environment Research Council (NERC, via grant NE/M013448/1).

William Carter acknowledges additional support of the University of California Retirement System for his work on this project.

Bernard Aumont, Ian Barnes, Wahid Mellouki, Bénédicte Picquet-Varrault and Andrew Rickard acknowledge support by the European Commission through EUROCHAMP-2020 (grant number 730997).

Mark Jacob Goldman was supported under the National Science Foundation Graduate Research Fellowship under Grant No. 1122374.

Funding was also provided to WR Stockwell by the California Air Resources Board through the University of California, Davis (Program, Peer Review of SAPRC-16 Chemical Mechanism and by the NOAA Center for Atmospheric Science-Meteorology (NCAS-M) which is funded by the National Atmospheric Administration/Educational Partnership Program under Cooperative Agreement \#NA16SEC4810006.

Peter Bräuer (University of York) is acknowledged for useful discussions. 


\section{Bibliography}

(1) Stockwell, W. R.; Lawson, C. V.; Saunders, E.; Goliff, W. S. Atmosphere 2012, 3 (1), 1-32.

(2) Calvert, J. G.; Orlando, J. J.; Stockwell, W. R.; Wallington, T. J. The mechanisms of reactions influencing atmospheric ozone; Oxford University Press: Oxford New York Aukland, 2015.

(3) Finlayson-Pitts, B. J.; Pitts, J. N. Chemistry of the Upper and Lower Atmosphere: Theory, Experiments, and Applications; Academic Press, San Diego, 2000.

(4) Goldstein, A. H.; Galbally, I. E. Environ Sci Technol 2007, 41 (5), 1514-1521.

(5) Aumont, B.; Szopa, S.; Madronich, S. Atmospheric Chem Phys 2005, 5 (9), 2497-2517.

(6) Jenkin, M. E.; Saunders, S. M.; Pilling, M. J. Atmos Environ 1997, 31 (1), 81-104.

(7) The Master Chemical Mechanism Website, MCM version 3.3.1 http://mcm.leeds.ac.uk/MCM/.

(8) Carter, W. P. Development of the SAPRC-07 chemical mechanism and updated ozone reactivity scales; California Air Resources Board, Research Division, 2007;

https://www.cert.ucr.edu/ carter/SAPRC/saprc07.pdf.

(9) Carter, W. P. L. Atmos Environ 2010, 44 (40), 5324-5335.

(10) Stockwell, W. R.; Middleton, P.; Chang, J.; Tang, X. J Geophys Res 1990, 95 (D10), 1634316367.

(11) Goliff, W. S.; Stockwell, W. R.; Lawson, C. V. Atmos Environ 2013, 68, 174-185.

(12) Stockwell, W. R.; Kirchner, F.; Kuhn, M.; Seefeld, S. J Geophys Res Atmospheres 1997, 102 (D22), 25847-25879.

(13) Sarwar, G.; Luecken, D.; Yarwood, G.; Whitten, G. Z.; Carter, W. P. L. J Appl Meteorol Climatol 2008, 47 (1), 3-14.

(14) Sarwar, G.; Godowitch, J.; Henderson, B. H.; Fahey, K.; Pouliot, G.; Hutzell, W. T.; Mathur, R.; Kang, D.; Goliff, W. S.; Stockwell, W. R. Atmos Chem Phys 2013, 13 (19), 9695-9712.

Eastham, S. D.; Weisenstein, D. K.; Barrett, S. R. H. Atmos Environ 2014, 89, 52-63.

Hewitt, H. T.; Copsey, D.; Culverwell, I. D.; Harris, C. M.; Hill, R. S. R.; Keen, A. B.; McLaren, A. J.; Hunke, E. C. Geosci Model Dev 2011, 4 (2), 223-253.

Morgenstern, O.; Braesicke, P.; O’Connor, F. M.; Bushell, A. C.; Johnson, C. E.; Osprey, S. M.; Pyle, J. A. Geosci Model Dev 2009, 2 (1), 43-57.

Kaduwela, A.; Luecken, D.; Carter, W.; Derwent, R. Atmos Environ 2015, 122, 609-610.

Calvert, J. G.; Atkinson, R.; Becker, K. H.; Kamens, R. M.; Seinfeld, J. H.; Wallington, T. J.;

Yarwood, G. The mechanisms of atmospheric oxidation of aromatic hydrocarbons; Oxford University Press: Oxford, New York, 2002.

Ehn, M.; Berndt, T.; Wildt, J.; Mentel, T. Int J Chem Kinet 2017, 49 (11), 821-831.

Ehn, M.; Thornton, J. A.; Kleist, E.; Sipilä, M.; Junninen, H.; Pullinen, I.; Springer, M.;

Rubach, F.; Tillmann, R.; Lee, B.; Lopez-Hilfiker, F.; Andres, S.; Acir, I.-H.; Rissanen, M.;

Jokinen, T.; Schobesberger, S.; Kangasluoma, J.; Kontkanen, J.; Nieminen, T.; Kurtén, T.;

Nielsen, L. B.; Jørgensen, S.; Kjaergaard, H. G.; Canagaratna, M.; Maso, M. D.; Berndt, T.; Petäjä, T.; Wahner, A.; Kerminen, V.-M.; Kulmala, M.; Worsnop, D. R.; Wildt, J.; Mentel, T. F. Nature 2014, 506 (7489), 476-479.

Yarwood, G.; Whitten, G. Z.; Jung, J.; Heo, G.; Allen, D. T. Development, evaluation and testing of version 6 of the Carbon Bond chemical mechanism (CB6), Final report to the Texas Commission on Environmental Quality, Work Order No. 582-7-84005-FY10-26; Texas Commission on Environmental Quality, 2012; http://aqrp.ceer.utexas.edu/viewprojects.cfm?Prop_Num=10-042. Carter, W. P. L. Atmospheric Environ Part Gen Top 1990, 24 (3), 481-518. Lurmann, F.; Carter, W. P. L.; Coyner, A. EPA-600/3-87-014a 1987.

Carter, W. P. L.; Lurmann, F. EPA-600/3-.90-001 1990.

Carter, W. P. L.; Lurmann, F. Atmos Environ 1991, 25A (12), 2771-2806. 
(27) Carlton, A. G.; Bhave, P. V.; Napelenok, S. L.; Edney, E. O.; Sarwar, G.; Pinder, R. W.;

Pouliot, G. A.; Houyoux, M. Environ Sci Technol 2010, 44 (22), 8553-8560.

(28) Griffin, R. J.; Dabdub, D.; Seinfeld, J. H. J Geophys Res-Atmospheres 2002, 107 (D17), 4332.

(29) Dimitriades, B. J Air Waste Manag Assoc 1999, 49 (7), 831-838.

(30) Carter, W. P. L. Air Waste 1994, 44 (7), 881-899.

(31) Madronich, S.; Calvert, J. G. The NCAR Master Mechanism of the Gas Phase ChemistryVersion 2.0; NCAR/TN-333+SRT; NCAR: Boulder Colorado, CO, USA, 1990.

Jenkin, M. E.; Derwent, R. G.; Wallington, T. J. Atmos Environ 2017, 163, 128-137.

Jenkin, M. E.; Young, J. C.; Rickard, A. R. Atmospheric Chem Phys 2015, 15 (20), 11433 11459.

Bloss, C.; Wagner, V.; Jenkin, M. E.; Volkamer, R.; Bloss, W. J.; Lee, J. D.; Heard, De.; Wirtz, K.; Martin-Reviejo, M.; Rea, G.; others. Atmospheric Chem Phys 2005, 5 (3), 641-664.

Jenkin, M. E.; Saunders, S. M.; Wagner, V.; Pilling, M. J. Atmospheric Chem Phys 2003, 3 (1), 181-193.

Saunders, S. M.; Jenkin, M. E.; Derwent, R. G.; Pilling, M. J. Atmospheric Chem Phys 2003, 3 (1), 161-180.

Jenkin, M. E.; Valorso, R.; Aumont, B.; Rickard, A. R.; Wallington, T. J. Atmospheric Chem Phys Discuss 2018, under review, DOI: 10.5194/acp-2018-145.

Jenkin, M. E.; Valorso, R.; Aumont, B.; Rickard, A. R.; Wallington, T. J. Atmospheric Chem Phys Discuss 2018, under review, DOI: 10.5194/acp-2018-146.

Blurock, E.; Battin-Leclerc, F.; Faravelli, T.; Green, W. H. In Cleaner Combustion: Developing

Detailed Chemical Kinetic Models; Battin-Leclerc, F., Simmie, J. M., Blurock, E., Eds.;

Springer-Verlag Berlin: Berlin, 2013; pp 59-92.

Carter, W. P. L. Gateway to the SAPRC-16 Mechanism Generation System;

http://mechgen.cert.ucr.edu/.

Valorso, R.; Aumont, B.; Camredon, M.; Raventos-Duran, T.; Mouchel-Vallon, C.; Ng, N. L.;

Seinfeld, J. H.; Lee-Taylor, J.; Madronich, S. Atmospheric Chem Phys 2011, 11 (14), 68956910.

Aumont, B.; Valorso, R.; Mouchel-Vallon, C.; Camredon, M.; Lee-Taylor, J.; Madronich, S. Atmospheric Chem Phys 2012, 12 (16), 7577-7589.

Aumont, B.; Camredon, M.; Mouchel-Vallon, C.; La, S.; Ouzebidour, F.; Valorso, R.; Lee-

Taylor, J.; Madronich, S. Faraday Discuss 2013, 165, 105-122.

Carter, W. P. L. Atmos Environ 2010, 44 (40), 5336-5345.

Camredon, M.; Aumont, B.; Lee-Taylor, J.; Madronich, S. Atmospheric Chem Phys 2007, 7

(21), 5599-5610.

Mouchel-Vallon, C.; Bräuer, P.; Camredon, M.; Valorso, R.; Madronich, S.; Herrmann, H.; Aumont, B. Atmospheric Chem Phys 2013, 13 (2), 1023-1037.

La, Y. S.; Camredon, M.; Ziemann, P. J.; Valorso, R.; Matsunaga, A.; Lannuque, V.; LeeTaylor, J.; Hodzic, A.; Madronich, S.; Aumont, B. Atmospheric Chem Phys 2016, 16 (3), 1417-1431.

McVay, R. C.; Zhang, X.; Aumont, B.; Valorso, R.; Camredon, M.; La, Y. S.; Wennberg, P. O.; Seinfeld, J. H. Atmospheric Chem Phys 2016, 16 (5), 2785-2802.

Lee-Taylor, J.; Madronich, S.; Aumont, B.; Baker, A.; Camredon, M.; Hodzic, A.; Tyndall, G. S.; Apel, E.; Zaveri, R. A. Atmospheric Chem Phys 2011, 11 (24), 13219-13241.

Lee-Taylor, J.; Hodzic, A.; Madronich, S.; Aumont, B.; Camredon, M.; Valorso, R.

Atmospheric Chem Phys 2015, 15 (2), 595-615.

Hodzic, A.; Madronich, S.; Aumont, B.; Lee-Taylor, J.; Karl, T.; Camredon, M.; Mouchel-

Vallon, C. Geophys Res Lett 2013, 40 (12), 3302-3307.

MAGNIFY Project: Mechanisms for Atmospheric chemistry: GeneratioN, Interpretation and 
FidelitY. Joint UK and French initiative aimed at developing the next generation of detail atmospheric chemical mechanisms. (Agence nationale de la recherche Grant ANR-14-CE010010 and UK Natural Environment Research Council Grant NE/M013448/1).

(53) Jenkin, M. E.; Watson, L. A.; Utembe, S. R.; Shallcross, D. E. Atmos Environ 2008, 42 (31), 7185-7195.

(54) Szopa, S.; Aumont, B.; Madronich, S. Atmospheric Chem Phys 2005, 5 (9), 2519-2538.

(55) Kirchner, F. Atmos Environ 2005, 39 (6), 1143-1159.

(56) Whitehouse, L. E.; Tomlin, A. S.; Pilling, M. J. Atmospheric Chem Phys 2004, 4 (7), 20572081.

(57) Aumont, B.; JaeckerVoirol, A.; Martin, B.; Toupance, G. Atmos Environ 1996, 30 (12), 20612077.

(58) Atkinson, R.; Arey, J. Chem Rev 2003, 103 (12), 4605-4638.

(59) Shetter, R. E.; Davidson, J. A.; Cantrell, C. A.; Calvert, J. G. Rev Sci Instrum 1987, 58 (8), 1427-1428.

(60) Anderson, P. N.; Hites, R. A. Environ Sci Technol 1996, 30 (1), 301-306.

(61) Leather, K. E.; McGillen, M. R.; Percival, C. J. Phys Chem Chem Phys 2010, 12 (12), 29352943.

(62) Glowacki, D. R.; Goddard, A.; Hemavibool, K.; Malkin, T. L.; Commane, R.; Anderson, F.; Bloss, W. J.; Heard, D. E.; Ingham, T.; Pilling, M. J.; Seakins, P. W. Atmospheric Chem Phys 2007, 7 (20), 5371-5390.

(63) McGillen, M. R.; Baasandorj, M.; Burkholder, J. B. J Phys Chem A 2013, 117 (22), 46364656.

(64) Porter, E.; Wenger, J.; Treacy, J.; Sidebottom, H.; Mellouki, A.; Teton, S.; LeBras, G. J Phys Chem A 1997, 101 (32), 5770-5775.

(65) Singleton, D. L.; Paraskevopoulos, G.; Irwin, R. S. J Am Chem Soc 1989, 111 (14), 52485251.

(66) Yatavelli, R. L. N.; Stark, H.; Thompson, S. L.; Kimmel, J. R.; Cubison, M. J.; Day, D. A.; Campuzano-Jost, P.; Palm, B. B.; Hodzic, A.; Thornton, J. A.; Jayne, J. T.; Worsnop, D. R.; Jimenez, J. L. Atmospheric Chem Phys 2014, 14 (3), 1527-1546.

(69) McGillen, M. R.; Carey, T. J.; Archibald, A. T.; Wenger, J. C.; Shallcross, D. E.; Percival, C. J. Phys Chem Chem Phys 2008, 10 (13), 1757-1768.

(70) McGillen, M. R.; Archibald, A. T.; Carey, T.; Leather, K. E.; Shallcross, D. E.; Wenger, J. C.; Percival, C. J. Phys Chem Chem Phys 2011, 13 (7), 2842-2849.

(71) Jokinen, T.; Sipila, M.; Richters, S.; Kerminen, V.-M.; Paasonen, P.; Stratmann, F.; Worsnop, D.; Kulmala, M.; Ehn, M.; Herrmann, H.; Berndt, T. Angew Chem-Int Ed 2014, 53 (52), 14596-14600.

(72) Crounse, J. D.; Knap, H. C.; Ørnsø, K. B.; Jørgensen, S.; Paulot, F.; Kjaergaard, H. G.; Wennberg, P. O. J Phys Chem A 2012, 116 (24), 5756-5762.

(73) Crounse, J. D.; Nielsen, L. B.; Jørgensen, S.; Kjaergaard, H. G.; Wennberg, P. O. J Phys Chem Lett 2013, 4 (20), 3513-3520.

(74) Kaiser, E. W. J Phys Chem A 2016, 120 (20), 3414-3423.

(75) McGillen, M. R.; Tyndall, G. S.; Orlando, J. J.; Pimentel, A. S.; Medeiros, D. J.; Burkholder, J. B. J Phys Chem A 2016, 120 (50), 9968-9981.

(76) Eurochamp Data Center. Simulation chamber data and data products; 2017; https://data.eurochamp.org/.

(77) Zádor, J.; Miller, J. A. Proc Combust Inst 2015, 35, 181-188.

(78) Zádor, J.; Nahm, H. N. In Joint meeting - US Sections of the Combustion Institute; Curran 
(79) Gao, C. W.; Allen, J. W.; Green, W. H.; West, R. H. Comput Phys Commun 2016, 203, 212 225.

(80) Barker, J. R.; Golden, D. M. Chem Rev 2003, 103 (12), 4577-4592.

(81) Vereecken, L.; Glowacki, D. R.; Pilling, M. J. Chem Rev 2015, 115 (10), 4063-4114.

(82) Burke, M. P.; Goldsmith, C. F.; Klippenstein, S. J.; Welz, O.; Huang, H.; Antonov, I. O.; Savee, J. D.; Osborn, D. L.; Zádor, J.; Taatjes, C. A.; Sheps, L. J Phys Chem A 2015, 119 (28), $7095-7115$.

(83) Jasper, A. W.; Oana, C. M.; Miller, J. A. Proc Combust Inst 2015, 35 (1), 197-204.

Barker, J. R.; Weston, R. E., Jr. J Phys Chem A 2010, 114 (39), 10619-10633.

Atkinson, R. Chem Rev 1986, 86 (1), 69-201.

Lightfoot, P.; Cox, R.; Crowley, J.; Destriau, M.; Hayman, G.; Jenkin, M.; Moortgat, G.; Zabel, F. Atmospheric Environ Part Gen Top 1992, 26 (10), 1805-1961.

Calvert, J. G.; Atkinson, R.; Kerr, J. A.; Madronich, S.; Wallington, T. J.; Yarwood, G. The mechanisms of atmospheric oxidation of the alkenes; Oxford University Press: New York, 2000

Calvert, J. G.; Derwent, R. G.; Orlando, J. J.; Tyndall, G. S.; Wallington, T. J. Mechanisms of the atmospheric oxidations of the alkanes; Oxford University Press, 2008.

Calvert, J. G.; Mellouki, A.; Orlando, J. J.; Pilling, M. J.; Wallington, T. J. The mechanisms of the atmospheric oxidations of the oxygenates; Oxford University Press, 2011.

IUPAC Kinetic Data Evaluation Panel. Task Group on Atmospheric Chemical Kinetic Data Evaluation. http://iupac.pole-ether.fr/.

NASA Panel for Data Evaluation. Chemical Kinetics and Photochemical Data for Use in Atmospheric Studies (https://jpldataeval.jpl.nasa.gov/), 2017.

Troe, J. J Phys Chem 1979, 83 (1), 114-126.

Cox, R. A. Chem Soc Rev 2012, 41 (19), 6231-6246.

Ammann, M.; Cox, R. A.; Crowley, J. N.; Jenkin, M. E.; Mellouki, A.; Rossi, M. J.; Troe, J.;

Wallington, T. J. Atmospheric Chem Phys 2013, 13 (16), 8045-8228.

Green, W. H.; Allen, J. W.; Buesser, B. A.; Ashcraft, R. W.; Beran, G. J. O.; Class, C. A.; Gao, C.; Goldsmith, C. F.; Harper, M. R.; Jalan, A.; Keceli, M.; Magoon, G. R.; Matheu, D. M.;

Merchant, S. S.; Mo, J. D.; Petway, S.; Raman, S.; Sharma, S.; Song, J.; Suleymanov, Y.; Van

Geem, K. M.; Wen, J.; West, R. H.; Wong, A.; Wong, H.-W.; Yelvington, P. E.; Yee, N.; Yu, J.

RMG - Reaction Mechanism Generator v4.0.1; http://rmg.sourceforge.net/, 2013.

(96) Sumathi, R.; Carstensen, H. H.; Green, W. H. J Phys Chem A 2001, 105 (39), 8969-8984.

(97) Méreau, R.; Rayez, M.-T.; Caralp, F.; Rayez, J.-C. Phys Chem Chem Phys 2000, 2 (17), $3765-$ 3772.

(98) Atkinson, R. Int J Chem Kinet 1980, 12 (10), 761-765.

(99) Yap, C. W. J Comput Chem 2011, 32 (7), 1466-1474.

(100) Marécal, V.; Peuch, V.-H.; Andersson, C.; Andersson, S.; Arteta, J.; Beekmann, M.;

Benedictow, A.; Bergstrom, R.; Bessagnet, B.; Cansado, A.; Cheroux, F.; Colette, A.; Coman, A.; Curier, R. L.; van der Gon, H. A. C. D.; Drouin, A.; Elbern, H.; Emili, E.; Engelen, R. J.; Eskes, H. J.; Foret, G.; Friese, E.; Gauss, M.; Giannaros, C.; Guth, J.; Joly, M.; Jaumouille, E.; Josse, B.; Kadygrov, N.; Kaiser, J. W.; Krajsek, K.; Kuenen, J.; Kumar, U.; Liora, N.; Lopez, E.; Malherbe, L.; Martinez, I.; Melas, D.; Meleux, F.; Menut, L.; Moinat, P.; Morales, T.; Parmentier, J.; Piacentini, A.; Plu, M.; Poupkou, A.; Queguiner, S.; Robertson, L.; Rouil, L.; Schaap, M.; Segers, A.; Sofiev, M.; Tarasson, L.; Thomas, M.; Timmermans, R.; Valdebenito, A.; van Velthoven, P.; van Versendaal, R.; Vira, J.; Ung, A. Geosci Model Dev 2015, 8 (9), 2777-2813.

(101) Potempski, S.; Galmarini, S. Atmospheric Chem Phys 2009, 9 (24), 9471-9489. 
(102) Johansson, L.; Epitropou, V.; Karatzas, K.; Karppinen, A.; Wanner, L.; Vrochidis, S.;

Bassoukos, A.; Kukkonen, J.; Kompatsiaris, I. Environ Model Softw 2015, 64, 143-155.

(103) Orlando, J. J.; Tyndall, G. S.; Wallington, T. J. Chem Rev 2003, 103 (12), 4657-4690.

(104) Atkinson, R. Atmos Environ 2007, 41 (38), 8468-8485.

(105) Vereecken, L.; Peeters, J. Phys Chem Chem Phys 2009, 11 (40), 9062-9074.

(106) Vereecken, L.; Peeters, J. Phys Chem Chem Phys 2010, 12 (39), 12608-12620.

(107) Newsome, B.; Evans, M. Atmospheric Chem Phys 2017, 17 (23), 14333-14352.

(108) Ridley, D. A.; Cain, M.; Methven, J.; Arnold, S. R. Geophys Res Lett 2017, 44 (14), $7472-$ 7481.

(109) Bergin, M. S.; Noblet, G. S.; Petrini, K.; Dhieux, J. R.; Milford, J. B.; Harley, R. A. Environ Sci Technol 1999, 33 (7), 1116-1126.

(110) Gao, D. F.; Stockwell, W. R.; Milford, J. B. J Geophys Res-Atmospheres 1996, 101 (D4), 9107-9119.

(111) Gao, D.; Stockwell, W.; Milford, J. J Geophys Res-Atmospheres 1995, 100 (D11), 2315323166.

(112) Russell, A.; Milford, J.; Bergin, M.; Mcbride, S.; Mcnair, L.; Yang, Y.; Stockwell, W.; Croes, B. Science 1995, 269 (5223), 491-495.

(113) Yang, Y.; Stockwell, W.; Milford, J. Environ Sci Technol 1995, 29 (5), 1336-1345.

(114) Manion, J. A.; Huie, R. E.; Levin, R. D.; Burgess Jr., D. R.; Orkin, V. L.; Tsang, W.; McGivern, W. S.; Hudgens, J. W.; knyazev, V. D.; Atkinson, D. B.; Chai, E.; Tereza, A. M.; Lin, C.-Y.; Allison, T. C.; Mallard, W. G.; Westley, F.; Herron, J. T.; Hampson, R. F.; Frizzell, D. H. NIST Chemical Kinetics Database - Standard Reference Database 17, Version 7.0 (Web Version), Release 1.6.8, Data Version 2017.07 http://kinetics.nist.gov/kinetics/.

(115) Zhou, C.-W.; Simmie, J. M.; Curran, H. J. Combust Flame 2011, 158 (4), 726-731.

(116) Atkinson, R. Int J Chem Kinet 1987, 19 (9), 799-828.

(117) McGillen, M. R.; Percival, C. J.; Raventos-Duran, T.; Sanchez-Reyna, G.; Shallcross, D. E. Atmos Environ 2006, 40 (14), 2488-2500.

(118) Estrada, E.; Matamala, A. R. J Chem Inf Model 2007, 47 (3), 794-804.

(131) Nguyen, T. B.; Tyndall, G. S.; Crounse, J. D.; Teng, A. P.; Bates, K. H.; Schwantes, R. H.; Coggon, M. M.; Zhang, L.; Feiner, P.; Milller, D. O.; Skog, K. M.; Rivera-Rios, J. C.; Dorris, M.; Olson, K. F.; Koss, A.; Wild, R. J.; Brown, S. S.; Goldstein, A. H.; de Gouw, J. A.; Brune, 
W. H.; Keutsch, F. N.; Seinfeldcj, J. H.; Wennberg, P. O. Phys Chem Chem Phys 2016, 18 (15), 10241-10254.

(132) Lewin, A. G.; Johnson, D.; Price, D. W.; Marston, G. Phys Chem Chem Phys 2001, 3 (7), $1253-1261$.

(133) Johnson, D.; Rickard, A. R.; McGill, C. D.; Marston, G. Phys Chem Chem Phys 2000, 2 (3), 323-328.

(134) Atkinson, R.; Carter, W. P. L. Chem Rev 1984, 84 (5), 437-470.

King, M. D.; Canosa-Mas, C. E.; Wayne, R. P. Phys Chem Chem Phys 1999, 1 (9), 2231-2238.

Pfrang, C.; King, M. D.; Canosa-Mas, C. E.; Wayne, R. P. Atmos Environ 2006, 40 (6), 1170 1179.

(137) Pfrang, C.; King, M. D.; Canosa-Mas, C. E.; Flugge, M.; Wayne, R. P. Atmos Environ 2007, 41 (8), 1792-1802.

(138) Pfrang, C.; King, M.; Braeckevelt, M.; Canosamas, C.; Wayne, R. Atmos Environ 2008, 42 (13), 3018-3034.

(139) Stewart, D. J.; Almabrok, S. H.; Lockhart, J. P.; Mohamed, O. M.; Nutt, D. R.; Pfrang, C.; Marston, G. Atmos Environ 2013, 70, 227-235.

(140) Ng, N. L.; Brown, S. S.; Archibald, A. T.; Atlas, E.; Cohen, R. C.; Crowley, J. N.; Day, D. A.; Donahue, N. M.; Fry, J. L.; Fuchs, H.; Griffin, R. J.; Guzman, M. I.; Herrmann, H.; Hodzic, A.; Iinuma, Y.; Jimenez, J. L.; Kiendler-Scharr, A.; Lee, B. H.; Luecken, D. J.; Mao, J.; McLaren, R.; Mutzel, A.; Osthoff, H. D.; Ouyang, B.; Picquet-Varrault, B.; Platt, U.; Pye, H. O. T.;

Rudich, Y.; Schwantes, R. H.; Shiraiwa, M.; Stutz, J.; Thornton, J. A.; Tilgner, A.; Williams, B. J.; Zaveri, R. A. Atmospheric Chem Phys 2017, 17 (3), 2103-2162.

(141) Kerdouci, J.; Picquet-Varrault, B.; Doussin, J.-F. ChemPhysChem 2010, 11 (18), 3909-3920.

Grosjean, D.; Williams, E. Atmospheric Environ Part Gen Top 1992, 26 (8), 1395-1405.

King, M. D.; Canosa-Mas, C. E.; Wayne, R. P. Phys Chem Chem Phys 1999, 1 (9), 2239-2246.

Gramatica, P.; Pilutti, P.; Papa, E. Qsar Comb Sci 2003, 22 (3), 364-373.

Gramatica, P.; Pilutti, P.; Papa, E. Atmos Environ 2003, 37 (22), 3115-3124.

Kerdouci, J.; Picquet-Varrault, B.; Doussin, J.-F. Atmos Environ 2014, 84, 363-372.

Thornton, J. A.; Kercher, J. P.; Riedel, T. P.; Wagner, N. L.; Cozic, J.; Holloway, J. S.; Dube, W. P.; Wolfe, G. M.; Quinn, P. K.; Middlebrook, A. M.; Alexander, B.; Brown, S. S. Nature 2010, 464 (7286), 271-274.

Poutsma, M. L. J Phys Chem A 2013, 117 (4), 687-703.

Teruel, M. A.; Achad, M.; Blanco, M. B. Chem Phys Lett 2009, 479 (1-3), 25-29.

Simpson, W. R.; von Glasow, R.; Riedel, K.; Anderson, P.; Ariya, P.; Bottenheim, J.; Burrows, J.; Carpenter, L. J.; Frieß, U.; Goodsite, M. E.; Heard, D.; Hutterli, M.; Jacobi, H.-W.;

Kaleschke, L.; Neff, B.; Plane, J.; Platt, U.; Richter, A.; Roscoe, H.; Sander, R.; Shepson, P.;

Sodeau, J.; Steffen, A.; Wagner, T.; Wolff, E. Atmospheric Chem Phys 2007, 7 (16), 43754418.

(151) Ramacher, B.; Orlando, J. J.; Tyndall, G. S. Int J Chem Kinet 2000, 32 (8), 460-465.

Bierbach, A.; Barnes, I.; Becker, K. H. Atmos Environ 1999, 33 (18), 2981-2992.

Barnes, I.; Bastian, V.; Becker, K.; Overath, R.; Zhu, T. Int J Chem Kinet 1989, 21 (7), 499517.

(154) Bierbach, A.; Barnes, I.; Becker, K. H. Int J Chem Kinet 1996, 28 (8), 565-577.

Ramacher, B.; Orlando, J. J.; Tyndall, G. S. Int J Chem Kinet 2001, 33 (3), 198-211.

Herron, J. T. J Phys Chem Ref Data 1988, 17 (3), 967-1026.

(157) Atkinson, R.; Aschmann, S. M.; Winer, A. M.; Pitts, J. N. Int J Chem Kinet 1984, 16 (6), 697706.

(158) Bernard, F.; Cazaunau, M.; Mu, Y.; Wang, X.; Daele, V.; Chen, J.; Mellouki, A. J Phys Chem A 2013, 117 (51), 14132-14140. 
(159) Jenkin, M. E.; Sulbaek Andersen, M. P.; Hurley, M. D.; Wallington, T. J.; Taketani, F.; Matsumi, Y. Phys Chem Chem Phys 2005, 7 (6), 1194-1204.

(160) King, M. D.; Canosa-Mas, C. E.; Wayne, R. P. Phys Chem Chem Phys 2002, 4 (2), 295-303.

(161) Orlando, J. J.; Tyndall, G. S. Chem Soc Rev 2012, 41 (19), 6294-6317.

(162) Carter, W. P. L.; Seinfeld, J. H. Atmos Environ 2012, 50 (Supplement C), 255-266.

(163) Nault, B. A.; Garland, C.; Pusede, S. E.; Wooldridge, P. J.; Ullmann, K.; Hall, S. R.; Cohen, R. C. Atmos Meas Tech 2015, 8 (2), 987-997.

(164) Andrews, D. U.; Heazlewood, B. R.; Maccarone, A. T.; Conroy, T.; Payne, R. J.; Jordan, M. J. T.; Kable, S. H. Science 2012, 337 (6099), 1203-1206.

(165) TUV. Tropospheric ultraviolet and visible (TUV) radiation model. https://www2.acom.ucar.edu/modeling/tropospheric-ultraviolet-and-visible-tuv-radiationmodel.

(166) Bais, A. F.; Madronich, S.; Crawford, J.; Hall, S. R.; Mayer, B.; van Weele, M.; Lenoble, J.; Calvert, J. G.; Cantrell, C. A.; Shetter, R. E.; Hofzumahaus, A.; Koepke, P.; Monks, P. S.; Frost, G.; McKenzie, R.; Krotkov, N.; Kylling, A.; Swartz, W. H.; Lloyd, S.; Pfister, G.; Martin, T. J.; Roeth, E.-P.; Griffioen, E.; Ruggaber, A.; Krol, M.; Kraus, A.; Edwards, G. D.; Mueller, M.; Lefer, B. L.; Johnston, P.; Schwander, H.; Flittner, D.; Gardiner, B. G.; Barrick, J.; Schmitt, R. J Geophys Res Atmospheres 2003, 108 (D16), 8543.

(167) Bohn, B.; Corlett, G. K.; Gillmann, M.; Sanghavi, S.; Stange, G.; Tensing, E.; Vrekoussis, M.; Bloss, W. J.; Clapp, L. J.; Kortner, M.; Dorn, H.-P.; Monks, P. S.; Platt, U.; Plass-Dülmer, C.; Mihalopoulos, N.; Heard, D. E.; Clemitshaw, K. C.; Meixner, F. X.; Prevot, A. S. H.; Schmitt, R. Atmos Chem Phys 2008, 8 (17), 5373-5391.

(168) Khan, S. S.; Broadbelt, L. J. Atmos Environ 2004, 38 (7), 1015-1022.

(169) Madronich, S.; Calvert, J. G. J Geophys Res Atmospheres 1990, 95 (D5), 5697-5715.

(170) Peeters, J.; Vereecken, L.; Fantechi, G. Phys Chem Chem Phys 2001, 3 (24), 5489-5504.

(171) Slagle, I. R.; Bernhardt, J. R.; Gutman, D. Symp Int Combust 1989, 22 (1), 953-962.

(172) Green, M.; Yarwood, G.; Niki, H. Int J Chem Kinet 1990, 22 (7), 689-699.

(173) Francisco, J.; Goldstein, A. Chem Phys 1988, 128 (2-3), 367-372.

(174) Méreau, R.; Rayez, M.-T.; Rayez, J.-C.; Caralp, F.; Lesclaux, R. Phys Chem Chem Phys 2001, 3 (21), 4712-4717.

(175) Curran, H. J.; Gaffuri, P.; Pitz, W. J.; Westbrook, C. K. Combust Flame 1998, 114 (1), 149177.

(176) Paulot, F.; Crounse, J. D.; Kjaergaard, H. G.; Kurten, A.; St. Clair, J. M.; Seinfeld, J. H.; Wennberg, P. O. Science 2009, 325 (5941), 730-733.

(177) Lin, Y.-H.; Zhang, H.; Pye, H. O. T.; Zhang, Z.; Marth, W. J.; Park, S.; Arashiro, M.; Cui, T.; Budisulistiorini, S. H.; Sexton, K. G.; Vizuete, W.; Xie, Y.; Luecken, D. J.; Piletic, I. R.; Edney, E. O.; Bartolotti, L. J.; Gold, A.; Surratt, J. D. Proc Natl Acad Sci 2013, 110 (17), 6718-6723.

(178) Fantechi, G.; Vereecken, L.; Peeters, J. Phys Chem Chem Phys 2002, 4 (23), 5795-5805.

(179) Vereecken, L.; Peeters, J. Phys Chem Chem Phys 2012, 14 (11), 3802-3815.

(180) Crounse, J. D.; Paulot, F.; Kjaergaard, H. G.; Wennberg, P. O. Phys Chem Chem Phys 2011, 13 (30), 13607-13613.

(181) Savee, J. D.; Papajak, E.; Rotavera, B.; Huang, H.; Eskola, A. J.; Welz, O.; Sheps, L.; Taatjes, C. A.; Zádor, J.; Osborn, D. L. Science 2015, 347 (6222), 643-646.

(182) Peeters, J.; Nguyen, T. L. J Phys Chem A 2012, 116 (24), 6134-6141.

(183) Peeters, J.; Müller, J.-F. J.; Stavrakou, T.; Nguyen, V. S. J Phys Chem A 2014, 118 (38), 86258643.

(184) Teng, A. P.; Crounse, J. D.; Wennberg, P. O. J Am Chem Soc 2017, 139 (15), 5367-5377.

(185) Groß, C. B. M.; Dillon, T. J.; Schuster, G.; Lelieveld, J.; Crowley, J. N. J Phys Chem A 2014 , 
$118(6), 974-985$.

(186) Winiberg, F. A. F.; Dillon, T. J.; Orr, S. C.; Groß, C. B. M.; Bejan, I.; Brumby, C. A.; Evans, M. J.; Smith, S. C.; Heard, D. E.; Seakins, P. W. Atmospheric Chem Phys 2016, 16 (6), 40234042.

(187) Hasson, A. S.; Tyndall, G. S.; Orlando, J. J. J Phys Chem A 2004, 108 (28), 5979-5989.

Hasson, A. S.; Tyndall, G. S.; Orlando, J. J.; Singh, S.; Hernandez, S. Q.; Campbell, S.; Ibarra, Y. J Phys Chem A 2012, 116 (24), 6264-6281.

(189) King, M. D.; Canosa-Mas, C. E.; Wayne, R. P. Atmos Environ 2001, 35 (12), 2081-2088.

Johnson, D.; Cassanelli, P.; Cox, R. A. Atmos Environ 2004, 38 (12), 1755-1765.

Raventos-Duran, M. T.; Percival, C. J.; McGillen, M. R.; Hamer, P. D.; Shallcross, D. E. Phys Chem Chem Phys 2007, 9 (31), 4338-4348.

(192) Vereecken, L.; Peeters, J. J Phys Chem A 2004, 108 (24), 5197-5204.

(193) Kaminski, M.; Fuchs, H.; Acir, I.-H.; Bohn, B.; Brauers, T.; Dorn, H.-P.; Häseler, R.;

Hofzumahaus, A.; Li, X.; Lutz, A.; Nehr, S.; Rohrer, F.; Tillmann, R.; Vereecken, L.; Wegener, R.; Wahner, A. Atmospheric Chem Phys 2017, 17 (11), 6631-6650.

(194) Berndt, T.; Richters, S.; Jokinen, T.; Hyttinen, N.; Kurten, T.; Otkjaer, R. V.; Kjaergaard, H. G.; Stratmann, F.; Herrmann, H.; Sipila, M.; Kulmala, M.; Ehn, M. Nat Commun 2016, 7, 13677.

(195) Glowacki, D. R.; Wang, L.; Pilling, M. J. J Phys Chem A 2009, 113 (18), 5385-5396.

(196) Birdsall, A. W.; Andreoni, J. F.; Elrod, M. J. J Phys Chem A 2010, 114 (39), 10655-10663.

(197) D’Arnbro, E. L.; Moller, K. H.; Lopez-Hilfiker, F. D.; Schobesberger, S.; Liu, J.; Shilling, J. E.; Lee, B. H.; Kjaergaard, H. G.; Thornton, J. A. Environ Sci Technol 2017, 51 (9), 4978-4987.

(198) Zádor, J.; Taatjes, C. A.; Fernandes, R. X. Prog Energy Combust Sci 2011, 37 (4), 371-421.

(199) Peeters, J.; Nguyen, T. L.; Vereecken, L. Phys Chem Chem Phys 2009, 11 (28), 5935-5939.

(200) Suh, I.; Zhang, R.; Molina, L. T.; Molina, M. J. J Am Chem Soc 2003, 125 (41), 12655-12665.

(201) Welz, O.; Savee, J. D.; Osborn, D. L.; Vasu, S. S.; Percival, C. J.; Shallcross, D. E.; Taatjes, C. A. Science 2012, 335 (6065), 204-207.

(202) Atkinson, R. Int J Chem Kinet 1997, 29 (2), 99-111.

(203) Baldwin, A.; Barker, J.; Golden, D.; Hendry, D. J Phys Chem 1977, 81 (25), 2483-2492.

(204) Carter, W. P. L.; Atkinson, R. J Atmospheric Chem 1985, 3 (3), 377-405.

(205) Choo, K. Y.; Benson, S. W. Int J Chem Kinet 1981, 13 (9), 833-844.

(206) Curran, H. J. Int J Chem Kinet 2006, 38 (4), 250-275.

(207) Peeters, J.; Fantechi, G.; Vereecken, L. J Atmospheric Chem 2004, 48 (1), 59-80.

(208) Johnson, D.; Cassanelli, P.; Cox, R. A. J Phys Chem A 2004, 108 (4), 519-523.

(209) Méreau, R.; Rayez, M.-T.; Caralp, F.; Rayez, J.-C. Phys Chem Chem Phys 2003, 5 (21), 48284833.

(210) Wallington, T. J.; Hurley, M. D.; Ball, J. C.; Straccia, A. M.; Platz, J.; Christensen, L. K.; Sehested, J.; Nielsen, O. J. J Phys Chem A 1997, 101 (29), 5302-5308.

(211) Henon, E.; Bohr, F.; Sokolowski-Gomez, N.; Caralp, F. Phys Chem Chem Phys 2003, 5 (24), 5431-5437.

(212) Thiriot, E.; Canneaux, S.; Hénon, E.; Bohr, F. React Kinet Catal Lett 2005, 85 (1), 123-129.

(213) Davis, A. C.; Francisco, J. S. J Am Chem Soc 2011, 133 (45), 18208-18219.

(214) Tuazon, E. C.; Carter, W. P. L.; Aschmann, S. M.; Atkinson, R. Int J Chem Kinet 1991, 23 (11), 1003-1015.

(215) Rayez, M.-T.; Picquet-Varrault, B.; Caralp, F.; Rayez, J.-C. Phys Chem Chem Phys 2002, 4 (23), 5789-5794.

(216) Pimentel, A. S.; Tyndall, G. S.; Orlando, J. J.; Hurley, M. D.; Wallington, T. J.; Sulbaek Andersen, M. P.; Marshall, P.; Dibble, T. S. Int J Chem Kinet 2010, 42 (8), 479-498.

(217) Wallington, T. J.; Hurley, M. D.; Maurer, T.; Barnes, I.; Becker, K. H.; Tyndall, G. S.; Orlando, 
J. J.; Pimentel, A. S.; Bilde, M. J Phys Chem A 2001, 105 (21), 5146-5154.

(218) Tyndall, G. S.; Pimentel, A. S.; Orlando, J. J. J Phys Chem A 2004, 108 (33), 6850-6856.

Orlando, J. J.; Tyndall, G. S. Int J Chem Kinet 2010, 42 (7), 397-413.

(220) Sander, W. Angew Chem Int Ed Engl 1990, 29 (4), 344-354.

(221) Gravestock, T. J.; Blitz, M. A.; Bloss, W. J.; Heard, D. E. Chemphyschem 2010, 11 (18), 39283941.

(222) Taatjes, C. A.; Shallcross, D. E.; Percival, C. Phys Chem Chem Phys 2014, 16, 1704-1718.

(223)

Asatryan, R.; Bozzelli, J. W. Phys Chem Chem Phys 2008, 10 (13), 1769.

McCarthy, M. C.; Cheng, L.; Crabtree, K. N.; Martinez, O.; Nguyen, T. L.; Womack, C. C.; Stanton, J. F. J Phys Chem Lett 2013, 4 (23), 4133-4139.

Donahue, N. M.; Drozd, G. T.; Epstein, S. A.; Presto, A. A.; Kroll, J. H. Phys Chem Chem Phys 2011, 13 (23), 10848-10857.

Kroll, J. H.; Sahay, S. R.; Anderson, J. G.; Demerjian, K. L.; Donahue, N. M. J Phys Chem A 2001, 105 (18), 4446-4457.

Nguyen, T. L.; Lee, H.; Matthews, D. A.; McCarthy, M. C.; Stanton, J. F. J Phys Chem A 2015, 119 (22), 5524-5533.

Nguyen, T. L.; Winterhalter, R.; Moortgat, G.; Kanawati, B.; Peeters, J.; Vereecken, L. Phys Chem Chem Phys 2009, 11 (21), 4173-4183.

Nguyen, T. L.; Peeters, J.; Vereecken, L. Phys Chem Chem Phys 2009, 11 (27), 5643-5656.

Zhang, D.; Lei, W.; Zhang, R. Chem Phys Lett 2002, 358 (3-4), 171-179.

Ahrens, J.; Carlsson, P. T. M.; Hertl, N.; Olzmann, M.; Pfeifle, M.; Wolf, J. L.; Zeuch, T.

Angew Chem Int Ed 2014, 53 (3), 715-719.

Vereecken, L.; Novelli, A.; Taraborrelli, D. Phys Chem Chem Phys 2017, 19, 31599-31612.

Khan, M. A. H.; Morris, W. C.; Galloway, M.; Shallcross, A.; Percival, C. J.; Shallcross, D. E. Int J Chem Kinet 2017, 49 (8), 611-621.

Novelli, A.; Hens, K.; Tatum Ernest, C.; Martinez, M.; Nölscher, A. C.; Sinha, V.; Paasonen, P.; Petäjä, T.; Sipilä, M.; Elste, T.; Plass-Dülmer, C.; Phillips, G. J.; Kubistin, D.; Williams, J.; Vereecken, L.; Lelieveld, J.; Harder, H. Atmospheric Chem Phys 2017, 17 (12), 7807-7826.

Percival, C.; Welz, O.; Eskola, A. J.; Savee, J. D.; Osborn, D. L.; Topping, D. O.; Lowe, D.; Utembe, S.; Bacak, A.; McFiggans, G.; Cooke, M.; Archibald, A. T.; Jenkin, M.; Derwent, R. G.; Riipinen, I.; Mok, D.; Lee, E. P. F.; Dyke, J.; Taatjes, C. A.; Shallcross, D. E. Faraday Discuss 2013, 165, 45-73.

Foreman, E. S.; Kapnas, K. M.; Murray, C. Angew Chem Int Ed 2016, 55 (35), 10419-10422. Caravan, R. L.; Khan, M. A. H.; Rotavera, B.; Papajak, E.; Antonov, I. O.; Chen, M.-W.; Au, K.; Chao, W.; Osborn, D. L.; Lin, J. J.-M.; Percival, C. J.; Shallcross, D. E.; Taatjes, C. A. Faraday Discuss 2017, 200, 313-330.

Smith, M. C.; Chao, W.; Kumar, M.; Francisco, J. S.; Takahashi, K.; Lin, J. J.-M. J Phys Chem A 2017, 121 (5), 938-945.

Vereecken, L.; Rickard, A. R.; Newland, M. J.; Bloss, W. J. Phys Chem Chem Phys 2015, 17, 23847-23858.

Vereecken, L.; Harder, H.; Novelli, A. Phys Chem Chem Phys 2012, 14 (42), 14682-14695.

Long, B.; Tan, X.; Long, Z.; Wang, Y.; Ren, D.; Zhang, W. J Phys Chem A 2011, 115 (24), 6559-6567.

Osborn, D. L.; Taatjes, C. A. Int Rev Phys Chem 2015, 34 (3), 309-360.

McGillen, M. R.; Curchod, B. F. E.; Chhantyal-Pun, R.; Beames, J. M.; Watson, N.; Khan, M. A. H. H.; McMahon, L.; Shallcross, D. E.; Orr-Ewing, A. J. ACS Earth Space Chem 2017, 1 (10), 664-672.

Beames, J. M.; Liu, F.; Lu, L.; Lester, M. I. J Am Chem Soc 2012, 134 (49), 20045-20048.

Lee, Y.-P. J Chem Phys 2015, 143 (2), 020901. 
(246) Kumar, M.; Francisco, J. S. Angew Chem Int Ed 2016, 55 (43), 13432-13435.

(247) Ruscic, B.; Feller, D.; Peterson, K. A. Theor Chem Acc 2013, 133 (1), 1415.

(248) Ruscic, B. J Phys Chem A 2015, 119 (28), 7810-7837.

(249) Somers, K. P.; Simmie, J. M. J Phys Chem A 2015, 119 (33), 8922-8933.

(250) Benson, S. W. Thermochemical Kinetics: Methods for the Estimation of Thermochemical Data and Rate Parameters, 2 edition.; Wiley: New York, 1976.

(251) Benson, S. W.; Buss, J. H. J Chem Phys 1958, 29, 546-572.

(252) Benson, S. W.; Cruickshank, F. R.; Golden, D. M.; Haugen, G. R.; O’Neal, H. E.; Rodgers, A. S.; Shaw, R.; Walsh, R. Chem Rev 1969, 69 (3), 279-324.

(253) Eigenmann, H. K.; Golden, D. M.; Benson, S. W. J Phys Chem 1973, 77 (13), 1687-1691.

(254) Lay, T. H.; Bozzelli, J. W.; Dean, A. M.; Ritter, E. R. J Phys Chem 1995, 99 (39), 1451414527.

(255) Cohen, N. J Phys Chem Ref Data 1996, 25 (6), 1411-1481.

(256) Khan, S. S.; Yu, X.; Wade, J. R.; Malmgren, R. D.; Broadbelt, L. J. J Phys Chem A 2009, 113 (17), 5176-5194.

(257) Ashcraft, R. W.; Green, W. H. J Phys Chem A 2008, 112 (38), 9144-9152.

(258) Vandeputte, A. G.; Sabbe, M. K.; Reyniers, M.-F.; Marin, G. B. Chem - Eur J 2011, 17 (27), 7656-7673.

(259) Paraskevas, P. D.; Sabbe, M. K.; Reyniers, M.-F.; Papayannakos, N.; Marin, G. B. Chem - Eur J 2013, 19 (48), 16431-16452.

(260) Khalfa, A.; Ferrari, M.; Fournet, R.; Sirjean, B.; Verdier, L.; Glaude, P. A. J Phys Chem A 2015, 119 (42), 10527-10539.

(261) Wang, H.; Castillo, Á.; Bozzelli, J. W. J Phys Chem A 2015, 119 (29), 8202-8215.

(262) Hudzik, J. M.; Bozzelli, J. W. J Phys Chem A 2017, 121 (23), 4523-4544.

(263) Song, G.; Bozzelli, J. W. J Phys Org Chem 2017, 30 (11), e3688.

(264) Goldsmith, C. F.; Magoon, G. R.; Green, W. H. J Phys Chem A 2012, 116 (36), 9033-9057.

(265) Klippenstein, S. J.; Harding, L. B.; Ruscic, B. J Phys Chem A 2017, 121 (35), 6580-6602.

(266) Simmie, J. M. J Phys Chem A 2015, 119 (42), 10511-10526.

(267) Simmie, J. M.; Sheahan, J. N. J Phys Chem A 2016, 120 (37), 7370-7384.

(268) Feller, D.; Peterson, K. A.; Ruscic, B. Theor Chem Acc 2013, 133 (1).

(269) Karton, A.; Daon, S.; Martin, J. M. L. Chem Phys Lett 2011, 510 (4-6), 165-178.

(270) Auzmendi-Murua, I.; Bozzelli, J. W. J Phys Chem A 2012, 116 (28), 7550-7563.

(271) Muller, C.; Michel, V.; Scacchi, G.; Come, G. M. J Chim Phys Phys-Chim Biol 1995, 92 (5), 1154-1178.

(272) Ritter, E. R.; Bozzelli, J. W. Int J Chem Kinet 1991, 23 (9), 767-778.

(273) Carter, W. P. L.; Heo, G. Atmos Environ 2013, 77, 404-414.

(274) Burcat, A. J Chem Eng Data 2009, 54 (6), 1829-1835. 